(1)

Check for

Cite as

Nano-Micro Lett.

(2020) 12:121

Received: 15 March 2020

Accepted: 6 May 2020

Published online: 6 June 2020

(C) The Author(s) 2020

\section{Insights into Enhanced Capacitive Behavior of Carbon Cathode for Lithium Ion Capacitors: The Coupling of Pore Size and Graphitization Engineering}

\author{
Kangyu Zou ${ }^{1}$, Peng Cai ${ }^{1}$, Baowei Wang ${ }^{1}$, Cheng $\mathrm{Liu}^{1}$, Jiayang $\mathrm{Li}^{1}$, Tianyun Qiu ${ }^{1}$, \\ Guoqiang Zou ${ }^{1}$, Hongshuai Hou ${ }^{1}$, Xiaobo $\mathrm{Ji}^{1,2}$ \\ $\bowtie$ Guoqiang Zou,gq-zou@csu.edu.cn \\ 1 College of Chemistry and Chemical Engineering, Central South University, Changsha 410083, \\ People's Republic of China \\ 2 College of Metallurgy and Chemical Engineering, Jiangxi University of Science and Technology, 86 Hongqi \\ Road, Ganzhou 341000, People's Republic of China
}

\title{
HIGHLIGHTS
}

- Pore size and graphitization engineering of carbon cathode were orientated-designed by regulating the molar ratios of $\mathrm{Zn} / \mathrm{Co}$ ions.

- $\mathrm{Zn}_{90} \mathrm{Co}_{10}$-APC and its assembled PLG//Zn ${ }_{90} \mathrm{Co}_{10}$-APC LIC both deliver the excellent electrochemical performances.

\begin{abstract}
The lack of methods to modulate intrinsic textures of carbon cathode has seriously hindered the revelation of in-depth relationship between inherent natures and capacitive behaviors, limiting the advancement of lithium ion capacitors (LICs). Here, an orientateddesigned pore size distribution (range from 0.5 to $200 \mathrm{~nm}$ ) and graphitization engineering strategy of carbon materials through regulating molar ratios of $\mathrm{Zn} / \mathrm{Co}$ ions has been proposed, which provides an effective platform to deeply evaluate the capacitive behaviors of carbon cathode. Significantly, after the systematical analysis cooperating with experimental result and density functional theory calculation, it is uncovered that the size of solvated $\mathrm{PF}_{6}{ }^{-}$ion is about $1.5 \mathrm{~nm}$. Moreover,

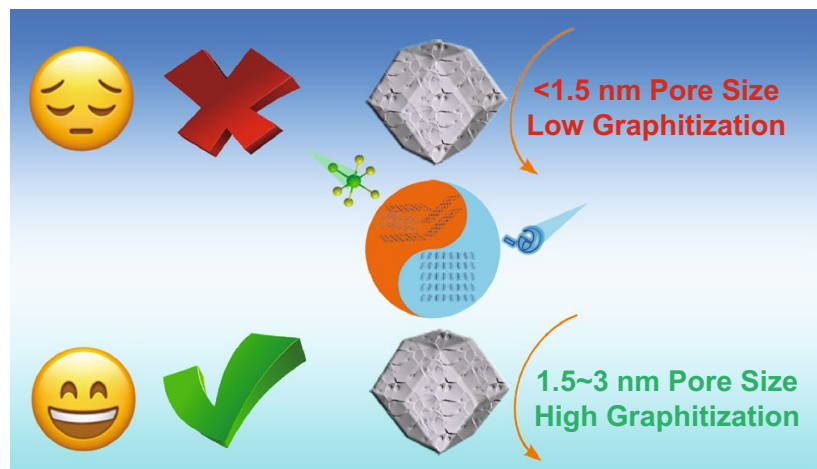

Carbon Cathode of Lithium Ion Capacitor the capacitive behaviors of carbon cathode could be enhanced attributed to the controlled pore size of 1.5-3 nm. Triggered with synergistic effect of graphitization and appropriate pore size distribution, optimized carbon cathode $\left(\mathrm{Zn}_{90} \mathrm{Co}_{10}\right.$-APC) displays excellent capacitive performances with a reversible specific capacity of $\sim 50 \mathrm{mAh} \mathrm{g}^{-1}$ at a current density of $5 \mathrm{~A} \mathrm{~g}^{-1}$. Furthermore, the assembly pre-lithiated graphite (PLG)//Zn ${ }_{90} \mathrm{Co}_{10}$-APC LIC could deliver a large energy density of $108 \mathrm{Wh} \mathrm{kg}^{-1}$ and a high power density of $150,000 \mathrm{~W} \mathrm{~kg}^{-1}$ as well as excellent long-term ability with 10,000 cycles. This elaborate work might shed light on the intensive understanding of the improved capacitive behavior in LiPF $_{6}$ electrolyte and provide a feasible principle for elaborate fabrication of carbon cathodes for LIC systems.
\end{abstract}

KEYWORDS Carbon materials; Pore size regulation; Graphitization; Capacitive behavior; Lithium ion capacitor 


\section{Introduction}

Lithium ion capacitor (LIC) is assembled by a battery-type anode and a capacitor-type cathode in a Li-salt electrolyte, elaborately combining the merits of high energy/power densities and long cycle life [1-4]. Nevertheless, the current electrochemcial performances of LICs are unsatisfactory, which are limited by the kinetic discrepancy between the sluggish intercalation/deintercalation mechanism of anode and fast adsorption/desorption behavior of cathode [5-7]. At the present time, enormous endeavors have been put into the researches for improving electrochemical kinetics of lithium intercalated/deintercalated behavior of carbon anodes [8-10]. It must be noticeable that energy/ power densities of LICs could be influenced by the electrochemical performances of cathode, due to the equation of $1 / C_{\text {cell }}=1 / C_{\text {anode }}+1 / C_{\text {cathode }}$ [11]. Therefore, the fabrication of high-performance carbon cathode is the crucial step for development of LICs. However, limited by uncontrolled intrinsic textures, the desired carbon cathodes could be hardly engineered. For example, however the widely used activated carbon (AC) cathodes (e.g., YP-50) have relatively large specific surface area $\left(\sim 1500 \mathrm{~m}^{2} \mathrm{~g}^{-1}\right)$, delivering unfavorable specific capacity $\left(<40 \mathrm{mAh} \mathrm{g}^{-1}\right)$. The presence of this dissatisfactory circumstance is ascribed to the narrow microporosity of $\mathrm{AC}$, which brings about the inefficiently storage of solvated $\mathrm{PF}_{6}{ }^{-}$ions [12]. Moreover, the low specific capacity exacerbates the difficulty of electrode fabrication, seriously hindering the improvement of LICs [13, 14]. To tackle this encountered problem, surface functionalization process has been implemented, which effectively improves the specific capacitance of commercial AC powder [15]. Furthermore, involving the pseudocapacitance reaction to carbon electrodes by heteroatom-doping method is a feasible strategy for promoting fast reaction kinetics and providing the additional capacity [16-18]. However, these aspects are not considered as the crucial factors for determining the intrinsic electrochemical performances of electric doublelayer capacitors (EDLCs) [19].

It is well known that the energy storage mechanism of EDLCs is governed by ion electrosorption at the electrode/ electrolyte surface and the electrochemical performances of EDLCs are mainly depended on the porous characteristics [20]. Thus, an appropriate pore size has been identified as a crucial parameter for boosting the electrochemical performance of EDLCs [21]. Generally, when the pore size of carbon matches with the solvated ion size, the maximized capacitance could be obtained. As a result, the optimization of pore size for carbon has been accounted as the key point to enhance the capacitance of EDLCs [22-24]. In addition, the graphitization also plays a vital role for increasing the capacitance of carbon materials, resulted from a high degree of electronic conductivity, which is difficultly adjusted [25]. Thus, a convenient and effective strategy for directionally adjusting pore size and graphitization of carbon materials should be urgently explored, which is beneficial to provide a fundamental outstanding in capacitive behavior. Nowadays, extensive research efforts have been dedicated to optimize the energy density of supercapacitor in tetraethylammonium tetrafluoroborate and ionic liquid electrolytes [26, 27]. Nevertheless, the capacitive behaviors of carbon materials in $\mathrm{LiPF}_{6}$ electrolyte have been rarely studied, limiting the progress of LICs. Hence, it is necessary to comprehensively explore the in-depth correlation between the micro-structure characteristics (including pore size dispersion and graphitization) and capacitive behavior of the carbon cathode, which could provide guidelines about improvement of LICs.

Zeolite imidazole frameworks (ZIFs), a well-known subfamily of metal-organic frameworks (MOFs), are constructed from the well-defined metal ions/clusters and organic ligands [28-31]. Due to the intrinsic merits of the highly ordered and adjustable structure, ZIFs have been chosen as an ideal sacrificial precursor for purposefully fabricating the carbon materials with diversified peculiarities [32-35]. In view of the above-mentioned considerations, aiming at the optimization of natures of carbon cathodes, MOF-derived carbon materials with different pore size distribution and graphitization have been orientated-engineered by regulating the molar ratios of $\mathrm{Zn} / \mathrm{Co}$ ions. After the systematical analysis through the collaborating with experimental result and DFT calculation, attributed to the presence of suitable pore size (1.5-3 nm), the capacitive behaviors of carbon materials could be enhanced on account of the strong adsorption/desorption of solvated $\mathrm{PF}_{6}{ }^{-}$ions. And the rate ability of carbon cathode could be boosted by improving the graphitization degree accompanied with enhanced electronic conductivity. Moreover, the improved graphitization and meso/macroporosities are beneficial for boosting surface-induced capacitive behavior of carbon cathode. Significantly, the engineered $\mathrm{Zn}_{90} \mathrm{Co}_{10}$-APC possesses the 
prominent natures combing the desired graphitization degree and appropriate pore size distribution, delivering superior electrochemical performances. This work provides a feasible strategy to regulate the micro-structure of carbon materials and benefits the deep understanding of the capacitive behaviors of carbon cathode affected by the pore size as well as graphitization, greatly promoting the electrochemical performance of LICs.

\section{Experimental Section}

\subsection{Materials and Methods}

\subsubsection{Preparation of $\mathrm{Zn}_{x} \mathrm{Co}_{100-x}-\mathrm{ZIFS}$}

For the synthesis of mono-metal-ZIFs (ZIF-8 ( $\mathrm{Zn}_{100-}$ ZIF) or ZIF-67 ( $\left.\mathrm{Co}_{100} \mathrm{ZIF}\right)$ ): $\mathrm{Zn}\left(\mathrm{NO}_{3}\right)_{2} \cdot 6 \mathrm{H}_{2} \mathrm{O}(3 \mathrm{mmol}, 891 \mathrm{mg})$ or $\mathrm{Co}\left(\mathrm{NO}_{3}\right)_{2} \cdot 6 \mathrm{H}_{2} \mathrm{O}(3 \mathrm{mmol}, 873 \mathrm{mg})$ was dissolved in $30 \mathrm{~mL}$ methanol, respectively. Then, 2-methylimidazole (984 mg, $12 \mathrm{mmol}$ ) was dissolved in another $30 \mathrm{~mL}$ methanol. Then, the later solution was added to the former solution and stirred. After a few minutes, the consequent solution was kept for $24 \mathrm{~h}$. Finally, the obtained product was washed with methanol and then dried at $80{ }^{\circ} \mathrm{C}$ under vacuum.

For the synthesis of bimetal-ZIFs: The preparation process was similar as method above but by regulating the molar ratio of $\mathrm{Zn}\left(\mathrm{NO}_{3}\right)_{2} \cdot 6 \mathrm{H}_{2} \mathrm{O}$ and $\mathrm{Co}\left(\mathrm{NO}_{3}\right)_{2} \cdot 6 \mathrm{H}_{2} \mathrm{O}$. Thus, $\mathrm{Zn}_{75} \mathrm{Co}_{25}$-ZIF, $\mathrm{Zn}_{50} \mathrm{Co}_{50}$-ZIF and $\mathrm{Zn}_{25} \mathrm{Co}_{75}$-ZIF were obtained with the different $\mathrm{Zn} / \mathrm{Co}$ radios (3:1, 1:1, and 1:3), respectively.

Note $\mathrm{x}$ represents the proportion of $\mathrm{Zn}$ element in $\mathrm{Zn}_{x} \mathrm{Co}_{100-x}$-ZIFs.

\subsubsection{Preparation of $\mathrm{Zn}_{x} \mathrm{Co}_{100-x}-\mathrm{PCs}$}

$\mathrm{Zn}_{x} \mathrm{Co}_{100-x}-\mathrm{ZIFs}$ were heat-treated in a tube furnace under an argon flow at $800{ }^{\circ} \mathrm{C}$ for $2 \mathrm{~h}$ with a heating rate of $10{ }^{\circ} \mathrm{C} \mathrm{min}{ }^{-1}$ and then cooled down to room temperature. In order to remove the residual metal impurities, the obtained products were washed with thoroughly HF solution and distilled water. The sample was finally dried under vacuum at $100{ }^{\circ} \mathrm{C}$ for $24 \mathrm{~h}$, which was correspondingly labeled as $\mathrm{Zn}_{x} \mathrm{Co}_{100-x}$-porous carbons $\left(\mathrm{Zn}_{x} \mathrm{Co}_{100-x}-\mathrm{PCs}\right)$, respectively.

\subsubsection{Fabrication of $\mathrm{Zn}_{x} \mathrm{Co}_{100-x}-\mathrm{APCs}$}

As-prepared $\mathrm{Zn}_{x} \mathrm{Co}_{100-x}-\mathrm{PCs}$ were thoroughly mixed with $\mathrm{KOH}$ in a mass ratio of $1: 1$. The mixture was further annealed at $800{ }^{\circ} \mathrm{C}$ for $1 \mathrm{~h}$ under argon atmosphere with a heating rate of $10{ }^{\circ} \mathrm{C} \mathrm{min}^{-1}$. The calcined samples were washed with diluted $\mathrm{HCl}$ and distilled water. The obtained specimen was dried under vacuum at $100{ }^{\circ} \mathrm{C}$ for $24 \mathrm{~h}$, which were correspondingly labeled as $\mathrm{Zn}_{x} \mathrm{Co}_{100-x}-\mathrm{APCs}$, respectively.

\subsection{Materials Characterization}

The structural information of the obtained samples was characterized by using a powder X-ray diffractometer (XRD, Rigaku) equipped with a $\mathrm{Cu}-\mathrm{K} \alpha$ radiation of $0.15418 \mathrm{~nm}$, and Raman spectra were recorded by using Raman spectrometer (DXR, Thermo-Fisher Scientific). $\mathrm{N}_{2}$ absorption/ desorption isotherms were collected by Micromeritics ASAP 2020 instrument, and the pore size distributions of samples were calculated by non-local density functional theory (NLDFT) method. Moreover, an X-ray photoelectron spectroscopy (XPS, VG Multi Lab 2000 system) was carried out for analyzing the compositions of the products. The surface morphology and inner structure were detected by scanning electron microscopy (SEM, Hitachi S-4800) and high-angle annular dark field scanning transmission electron microscopy (HAADF-STEM, Titan G2 60-300). Electronic conductivity is reciprocal of electronic resistivity, and electronic resistivity of carbon membrane was carried out at room temperature under $0.55 \mathrm{~T}$ magnetic field using the van der Pauw method by the Hall measurement (ECOPIA HMS 3000). Moreover, the carbon membrane was prepared with grinding apparatus by using the powder compressing machine under the $10 \mathrm{MPa}$.

\subsection{Electrochemical Measurements}

The MOF-derived carbon cathodes were prepared by mixing $80 \mathrm{wt} \%$ active materials $\left(\mathrm{Zn}_{x} \mathrm{Co}_{100-x}-\mathrm{PCs}\right.$ and $\left.\mathrm{Zn}_{x} \mathrm{Co}_{100-x}-\mathrm{APCs}\right), 10 \mathrm{wt} \%$ binder polyvinylidene fluoride (PVDF), and $10 \mathrm{wt} \%$ conductive carbon (Super P) in N-methyl pyrrolidinone (NMP). Afterward, the resulting mixtures were coated on an aluminum foil and the as-obtained electrodes were dried at $80{ }^{\circ} \mathrm{C}$ for $12 \mathrm{~h}$ in a 
vacuum box. Meanwhile, the commercial graphite anode was acquired by the similar method as the cathode. The mixed slurries were consisted of the $70 \mathrm{wt} \%$ active material, $15 \mathrm{wt} \%$ binder carboxymethyl cellulose, and $15 \mathrm{wt} \%$ conductive carbon (Super P) in deionized water, which were subsequently bushed on a copper foil.

The half-cells of working electrodes (both the anode and cathode) were assembled into a series of CR2016-type coins in the Braun glovebox with high-purity argon atmosphere. The lithium metal was used as the counter and reference electrode, and a Whatman GF/C glass fiber membrane was utilized the separator. Moreover, $1 \mathrm{~mol} \mathrm{~L}^{-1} \mathrm{LiPF}_{6}$ solution in ethylene carbonate (EC) and dimethyl carbonate (DMC) $(1: 1, \mathrm{v} / \mathrm{v})$ with $5 \mathrm{wt} \%$ fluoroethylene carbonate was severed as the electrolyte. The graphite anode was cycled for 5 cycles in a half-cell versus $\mathrm{Li} / \mathrm{Li}^{+}$under $0.1 \mathrm{~A} \mathrm{~g} \mathrm{~g}^{-1}$, which is beneficial for assembling the LICs.

All electrochemical measurements were measured at room temperature. Cyclic voltammetry (CV) curves with various scan rates and electrochemical impedance spectra (EIS) were measured by a MULTI AUTOLAB M204 (MAC90086). Galvanostatic charge/discharge (GCD) surveys were recorded on an Arbin BT2000 instrument at diverse current densities within an appropriate voltage window. Cycle-life tests for half-cells and LICs were recorded on a battery system (Land CT2001 A model).

The specific capacitance $\left(\mathrm{C}, \mathrm{F} \mathrm{g}^{-1}\right)$, energy density (E, $\mathrm{W} \mathrm{h} \mathrm{kg}{ }^{-1}$ ), and power density ( $\mathrm{P}, \mathrm{W} \mathrm{kg}^{-1}$ ) of LICs, based on the GCD measurements, can be calculated according to Eqs. 1-3:

$C=I t / \Delta V m$

$E=C\left(V_{\max }^{2}-V_{\min }^{2}\right) / 2 \times 3.6$

$P=E \times 3600 / t$

where $V_{\max }(\mathrm{V})$ and $V_{\text {min }}(\mathrm{V})$ are the maximum and minimum discharge potentials, $\Delta V(\mathrm{~V})$ is the potential change, $I(\mathrm{~A})$ is the discharge current, $t(\mathrm{~s})$ is the discharge time, and $m(\mathrm{~g})$ is the total mass of active material in both anode and cathode.

\subsection{DFT Calculations}

The DFT calculations were calculated for the solvated structures of $\mathrm{PF}_{6}{ }^{-}$ion by EC and DMC molecules, utilizing the
Perdew-Burke-Ernzerhof (PBE) exchange-correlation functional within the framework of generalized gradient approximation (GGA). The numerical foundational settings were employed for valid computation of wave functions. Moreover, the analytical foundational set functions spend longer than numerical foundational settings. Furthermore, the architectonic optimization of the solvation structures and their energies were obtained by the triple-numerical polarization (TNP) foundational settings (one atomic orbital (AO) for each occupied atomic orbital, the second and the third settings of valence AO's, $d$-functions for non-hydrogen atoms, and $p$-functions on hydrogen atoms). The combination of the functional and the foundational settings as GGA$\mathrm{PBE} / \mathrm{TNP}$ was referred in this system. The calculation for the $\mathrm{PF}_{6}{ }^{-}$ion solvation was achieved in the gas phase without the presence of the counter cation $\mathrm{Li}^{+}$. All atomic positions were refined during the optimization procedure.

\section{Results and Discussions}

\subsection{Characterization and Morphology}

It is well known that ZIF-8 and ZIF-67 are isologues, which are fabricated by the reactions of 2-methyl imidazole with zinc and cobalt ions, respectively [36]. Moreover, the bimetallic ZIFs obtained by controlling the molar ratios of zinc to cobalt ions $\left(\mathrm{Zn}^{2+} / \mathrm{Co}^{2+}\right)$ have been deduced to possess the same crystalline state as monometallic ZIF [37-39]. The as-prepared $\mathrm{Zn}_{x} \mathrm{Co}_{100-x}$ ZIFs have been firstly characterized by XRD measurements. As shown in Fig. S1, the samples exhibit the same XRD peaks, which certifies that the high phase purity and same topological structure. The experimental XRD pictures of $\mathrm{Zn}_{x} \mathrm{Co}_{100-x}$-ZIFs are almost the same, which are identical to the corresponding computer-simulated pattern, indicating the isomorphism of $\mathrm{Zn}_{x} \mathrm{Co}_{100-x}$-ZIFs. As shown in Fig. 1a, two obvious peaks are centered at $\sim 25^{\circ}$ and $\sim 44^{\circ}$ which are ascribed to the (002) and (100) planes of carbon, respectively [40, 41]. Due to the broad diffraction peaks with low densities, $\mathrm{Zn}_{100}$-PC manifests mainly amorphous characteristic in nature [42-44]. On the other aspect, the full-width at half maximum of the (002) peak of $\mathrm{Co}_{100}$-PC becomes narrow, attributed to remarkable graphitization effect of cobalt species triggered by the partially filled $3 \mathrm{~d}$ orbitals [45-47]. Furthermore, as the proportion of cobalt ions increases, the 
crystallinities of $\mathrm{Zn}_{x} \mathrm{Co}_{100-x}-\mathrm{PCs}$ are gradually improved. Significantly, it is noted that $\mathrm{Zn}_{x} \mathrm{Co}_{100-x}$ APCs also show the high graphitization degrees even after $\mathrm{KOH}$ chemical activation (Fig. 1b). To further verify the graphitization degree of carbon materials, the Raman spectra of $\mathrm{Zn}_{x} \mathrm{Co}_{100-x}-\mathrm{PCs}$ and $\mathrm{Zn}_{x} \mathrm{Co}_{100-x}-\mathrm{APCs}$ are recorded. As shown in Fig. 1c, d, two characteristic peaks are centered at around 1350 and $1585 \mathrm{~cm}^{-1}$, respectively, corresponding to D bands (disorder-induced carbon) and G-bands (graphitized carbon) [48-50]. The relative $I_{D} / I_{G}$ ratios are 1.46, 1.34, 1.27, 1.15, and 1.05 for $\mathrm{Zn}_{100}-\mathrm{PC}, \mathrm{Zn}_{75} \mathrm{Co}_{25}-\mathrm{PC}$, $\mathrm{Zn}_{50} \mathrm{Co}_{50}-\mathrm{PC}, \mathrm{Zn}_{25} \mathrm{Co}_{75}-\mathrm{PC}$, and $\mathrm{Co}_{100}-\mathrm{PC}$, demonstrating that the graphitization degree of $\mathrm{Zn}_{x} \mathrm{Co}_{100-x}-\mathrm{PCs}$ could be enhanced as the proportion of cobalt ions. Meanwhile, the $I_{D} / I_{G}$ values for the $\mathrm{Zn}_{x} \mathrm{Co}_{100-x}$-APCs are 1.86 ( $\mathrm{Zn}_{100}$-APC), $1.51\left(\mathrm{Zn}_{75} \mathrm{Co}_{25}\right.$-APC), $1.37\left(\mathrm{Zn}_{50} \mathrm{Co}_{50}\right.$-APC),
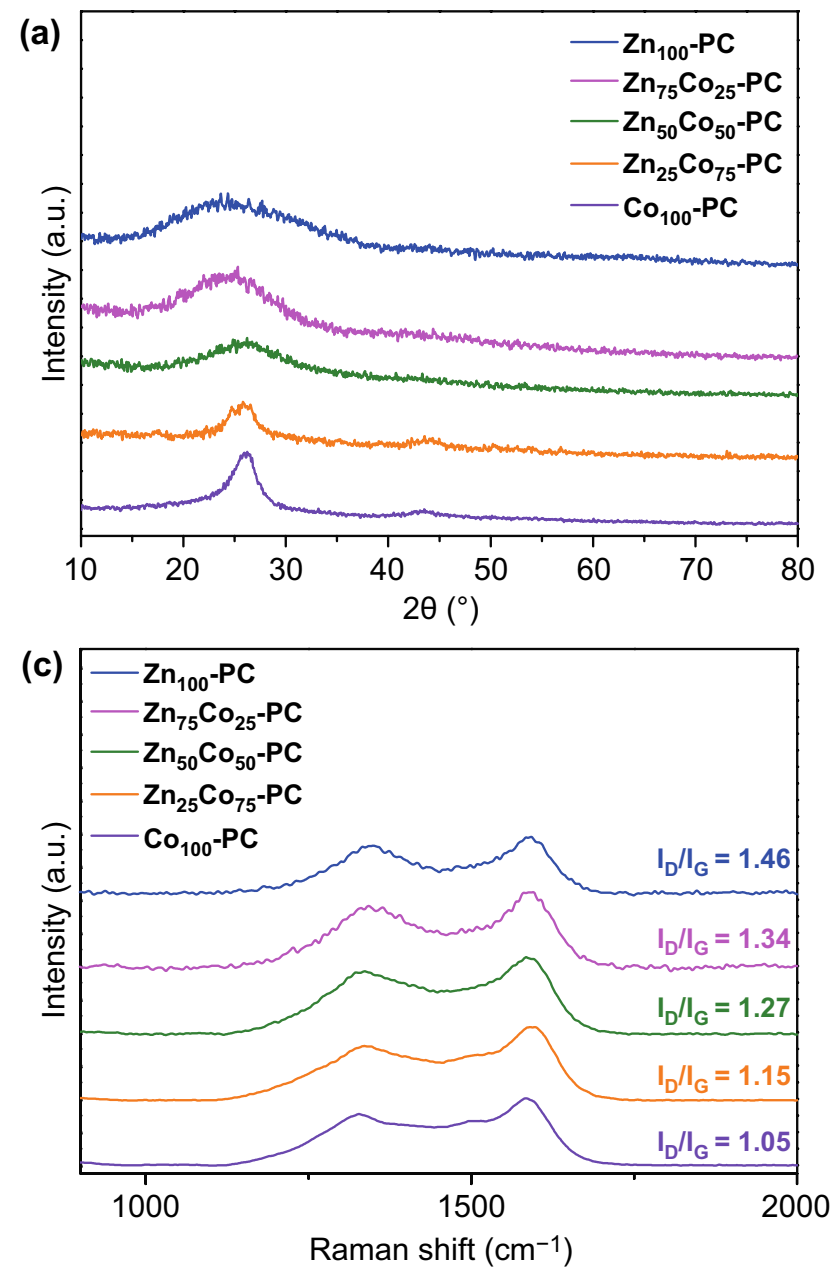

$1.31\left(\mathrm{Zn}_{25} \mathrm{Co}_{75}\right.$-APC), and $1.24\left(\mathrm{Co}_{100}-\mathrm{APC}\right)$, respectively. Moreover, the electronic conductivities of $\mathrm{Zn}_{100}-\mathrm{PC}$, $\mathrm{Zn}_{75} \mathrm{Co}_{25}-\mathrm{PC}, \mathrm{Zn}_{50} \mathrm{Co}_{50}-\mathrm{PC}, \mathrm{Zn}_{25} \mathrm{Co}_{75}-\mathrm{PC}$, and $\mathrm{Co}_{100}-\mathrm{PC}$ samples are about $0.10 \mathrm{~S} \mathrm{~cm}^{-1}, 1.12 \mathrm{~S} \mathrm{~cm}^{-1}, 5.42 \mathrm{~S} \mathrm{~cm}^{-1}$, $8.70 \mathrm{~S} \mathrm{~cm}^{-1}$, and $12.5 \mathrm{~S} \mathrm{~cm}^{-1}$. And, the electronic conductivities of $\mathrm{Zn}_{100}-\mathrm{APC}, \mathrm{Zn}_{75} \mathrm{Co}_{25}-\mathrm{APC}, \mathrm{Zn}_{50} \mathrm{Co}_{50}$-APC, $\mathrm{Zn}_{25} \mathrm{Co}_{75}$-APC, and $\mathrm{Co}_{100}$-APC samples are approximately $0.05,0.89,4.20,6.70$, and $9.50 \mathrm{~S} \mathrm{~cm}^{-1}$, respectively. The results above clearly demonstrate the enhancement of the electronic conductivity stems from the gradually increscent graphitization degree. Therefore, the graphitization degree of carbon materials could be adjusted by regulating the molar ratio of $\mathrm{Zn} / \mathrm{Co}$ ions.

The porous features of $\mathrm{Zn}_{x} \mathrm{Co}_{100-x}-\mathrm{PCs}$ and $\mathrm{Zn}_{x} \mathrm{Co}_{100-x}$-APCs have been explored by $\mathrm{N}_{2}$ adsorption-desorption isothermal analyses at $77 \mathrm{~K}$, which are
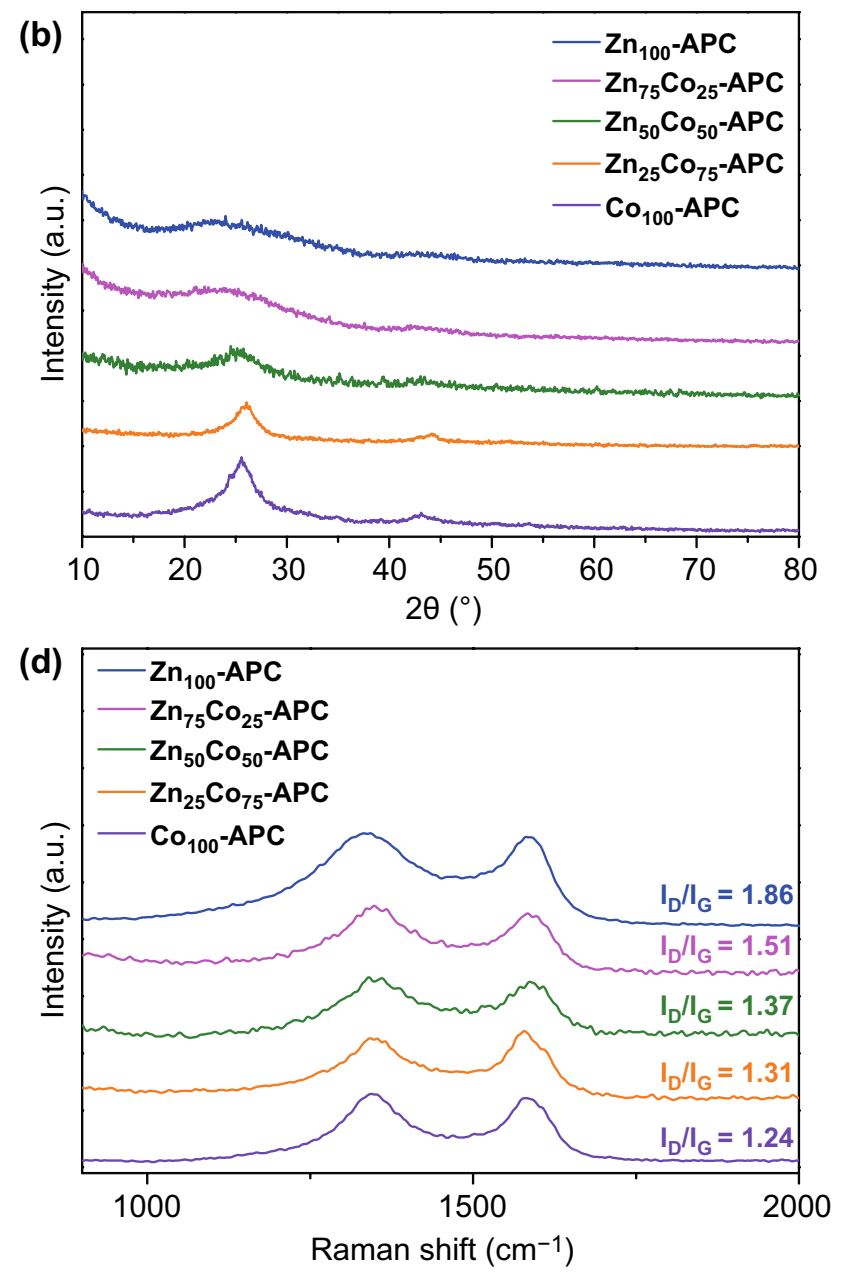

Fig. 1 The XRD patterns and Raman spectra of $\mathbf{a}, \mathbf{b} \mathrm{Zn}_{x} \mathrm{Co}_{100-x} \mathrm{PCs}$ and $\mathbf{c}, \mathbf{d} \mathrm{Zn}_{x} \mathrm{Co}_{100-x} \mathrm{APCs}$ 
summarized in Table 1. As displayed in Fig. 2a, it is obvious that the curve of $\mathrm{Zn}_{100}-\mathrm{PC}$ presents the classical type I, which illustrates the dominant micropore structure, resulted from the leave of $\mathrm{Zn}$ vapor at relatively high temperature $[51,52]$. It is noteworthy that the typical type $\mathrm{H} 3$ hysteresis loop within the $P / P_{0}$ range of $0.45-1.0$ becomes gradually wider as the increased proportion of cobalt source, revealing the existence of meso-/macro-pores with a broad size distribution [53]. This phenomenon mainly is attributed to removal of Co species on the carbon substance. It is found that the BET specific surface areas are gradually decreased in order of $\mathrm{Zn}_{100}-\mathrm{PC}\left(957 \mathrm{~m}^{2} \mathrm{~g}^{-1}\right)>\mathrm{Zn}_{75} \mathrm{Co}_{25}-\mathrm{PC}\left(524 \mathrm{~m}^{2}\right.$ $\left.\mathrm{g}^{-1}\right)>\mathrm{Zn}_{50} \mathrm{Co}_{50}$-PC $\left(370 \mathrm{~m}^{2} \mathrm{~g}^{-1}\right)>\mathrm{Zn}_{25} \mathrm{Co}_{75^{-}}$-PC $\left(367 \mathrm{~m}^{2}\right.$ $\left.\mathrm{g}^{-1}\right)>\mathrm{Co}_{100}-\mathrm{PC}\left(332 \mathrm{~m}^{2} \mathrm{~g}^{-1}\right)$. The results above show that carbon structure with different surface area and pore size can be designed by adjusting the molar ratio of $\mathrm{Zn} / \mathrm{Co}$ ions. It is all known that $\mathrm{KOH}$ chemical activation could enlarge the BET specific surface area and change the porosity characteristic of carbon material [54-57]. Thus, it is obvious that $\mathrm{Zn}_{x} \mathrm{Co}_{100-x}$-APCs exhibit the hierarchical porous structures with enlarged specific surface areas and abundant meso-/ macro-porosities (Fig. 2b). In addition, Fig. 2c, d shows the pore size distributions of all samples. In order to further assess the difference in pore size distribution, the normalized cumulative pore size distributions of $\mathrm{Zn}_{x} \mathrm{Co}_{100-x}-\mathrm{PCs}$ and $\mathrm{Zn}_{x} \mathrm{Co}_{100-x}$-APCs have been carefully analyzed (Fig. 2e, f). And, the comparison of normalized cumulative pore volume could offer a direct evidence for assessing the change of pore features [58]. Generally, often-used volume weighted average pore size $d_{50}$ does not fully represent the pore size distribution width. Thus, $d_{25}$ and $d_{75}$, serving as the pore width encompassing $25 \%$ and $75 \%$ of the total pore volume, are added for showing the comprehensive distribution width of carbon materials, respectively. Significantly, the comprehensive pore distribution is anticipated to provide an important parameter to analyze the relationship between pore size distribution and capacitive behavior of carbon cathode in the later content.

In order to intuitively observe the changes of morphologies and porous structures, the SEM and HRTEM images of $\mathrm{Zn}_{100}-\mathrm{PC}, \mathrm{Co}_{100}-\mathrm{PC}, \mathrm{Zn}_{100}-\mathrm{APC}$, and $\mathrm{Co}_{100}-\mathrm{APC}$ are displayed in Fig. 3. The above samples manifest rhombic dodecahedral shape. Significantly, it is found that $\mathrm{Zn}_{100}-\mathrm{PC}$ distinctly is the amorphous characteristic with dominated microporous feature and $\mathrm{Co}_{100}$-PC manifests the graphitized carbon layers with prominent meso-/macro-porosities. Furthermore, the graphitic ribbons with $0.34 \mathrm{~nm}$ lattice fringes are noticed [59]. Meanwhile, after $\mathrm{KOH}$ chemical activation, $\mathrm{Zn}_{100}$-APC obviously possesses the meso-/macro-porosities and $\mathrm{Co}_{100}$-APC exhibits the uniform and shrunken meso-/macro-pores. These discussed results are well consistent with the above-mentioned analyzed results of XRD, Raman and porosity.

\subsection{Electrochemical Performance of Carbon Cathode}

To evaluate the adsorption/desorption of the solvated anion $\left(\mathrm{PF}_{6}{ }^{-}\right)$behaviors of the obtained specimens as the cathodes of LICs, the half-cell tests versus lithium metal have been investigated within the potential range of $2.0-4.5 \mathrm{~V}$. As

Table 1 Summary of the porosity parameters for as-prepared samples

\begin{tabular}{|c|c|c|c|c|c|c|}
\hline Sample & $\begin{array}{l}S_{\mathrm{BET}} \\
\left(\mathrm{m}^{2} \mathrm{~g}^{-1}\right)\end{array}$ & $\begin{array}{l}V_{\text {total }} \\
\left(\mathrm{cm}^{3} \mathrm{~g}^{-1}\right)\end{array}$ & $\begin{array}{l}V_{\text {mirco }} \\
\left(\mathrm{cm}^{3} \mathrm{~g}^{-1}\right)\end{array}$ & $\begin{array}{l}d_{25} \\
(\mathrm{~nm})\end{array}$ & $\begin{array}{l}d_{50} \\
(\mathrm{~nm})\end{array}$ & $\begin{array}{l}d_{75} \\
(\mathrm{~nm})\end{array}$ \\
\hline $\mathrm{Zn}_{100}-\mathrm{PC}$ & 957 & 0.53 & 0.26 & 0.73 & 1.25 & 1.90 \\
\hline $\mathrm{Zn}_{75} \mathrm{Co}_{25}-\mathrm{PC}$ & 524 & 0.87 & 0.19 & 10.06 & 33.75 & 51.60 \\
\hline $\mathrm{Zn}_{50} \mathrm{Co}_{50}-\mathrm{PC}$ & 370 & 0.58 & 0.12 & 1.51 & 33.40 & 48.16 \\
\hline $\mathrm{Zn}_{25} \mathrm{Co}_{75}-\mathrm{PC}$ & 367 & 0.85 & 0.01 & 7.52 & 28.66 & 42.51 \\
\hline $\mathrm{Co}_{100}-\mathrm{PC}$ & 332 & 0.29 & 0.06 & 1.18 & 2.07 & 27.27 \\
\hline $\mathrm{Zn}_{100}-\mathrm{APC}$ & 2073 & 1.17 & 0.30 & 1.23 & 2.12 & 2.64 \\
\hline $\mathrm{Zn}_{75} \mathrm{Co}_{25}-\mathrm{APC}$ & 1385 & 1.16 & 0.23 & 2.11 & 2.96 & 17.37 \\
\hline $\mathrm{Zn}_{50} \mathrm{Co}_{50}-\mathrm{APC}$ & 881 & 1.09 & 0.42 & 2.51 & 4.68 & 40.07 \\
\hline $\mathrm{Zn}_{25} \mathrm{Co}_{75}-\mathrm{APC}$ & 585 & 0.88 & 0.03 & 3.19 & 7.31 & 28.61 \\
\hline $\mathrm{Co}_{100}-\mathrm{APC}$ & 573 & 0.84 & 0.04 & 2.93 & 6.71 & 33.08 \\
\hline $\mathrm{Zn}_{90} \mathrm{Co}_{10}-\mathrm{APC}$ & 1535 & 1.18 & 0.24 & 1.81 & 2.82 & 7.17 \\
\hline
\end{tabular}



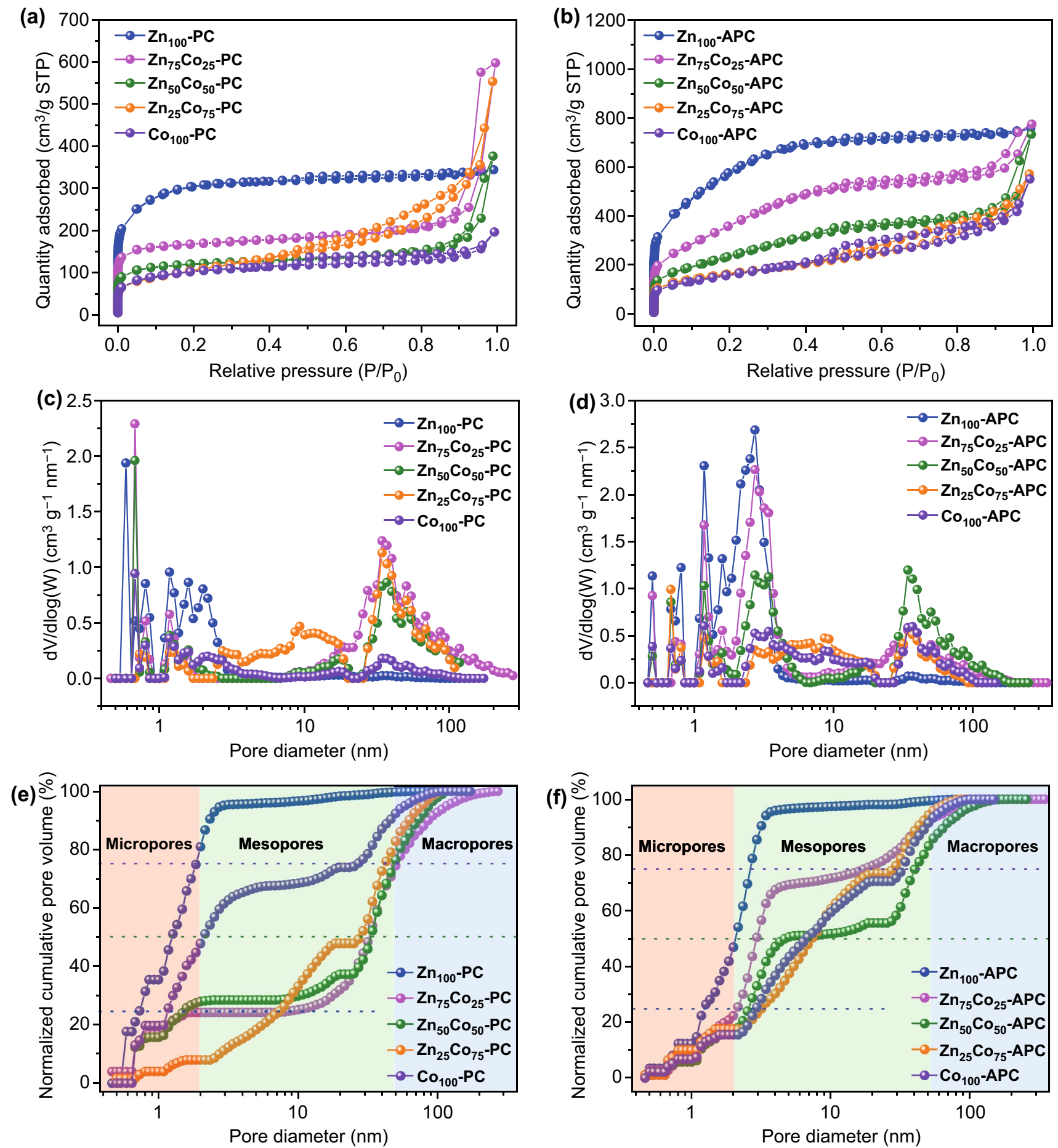

Fig. 2 a , b $\mathrm{N}_{2}$ adsorption-desorption isotherms, $\mathbf{c}, \mathbf{d}$ pore size distribution curves and $\mathbf{e}, \mathbf{f}$ normalized cumulative pore size distributions of $\mathrm{Zn}_{x} \mathrm{Co}_{100-x}-\mathrm{PCs}$ and $\mathrm{Zn}_{x} \mathrm{Co}_{100-x}-\mathrm{APCs}$

shown in Fig. 4a-d, rate performances of $\mathrm{Zn}_{x} \mathrm{Co}_{100-x}-\mathrm{PCs}$ and $\mathrm{Zn}_{x} \mathrm{Co}_{100-x}-\mathrm{APCs}$ at various current densities are presented. Moreover, the corresponding coulombic efficiencies have been shown in Figs. S2 and S3. It is noticed that $\mathrm{Zn}_{100}$-PC possesses the worst electrochemical performances among the $\mathrm{Zn}_{x} \mathrm{Co}_{100-x}-\mathrm{PCs}$, only delivering $15 \mathrm{mAh} \mathrm{g}^{-1}$ 

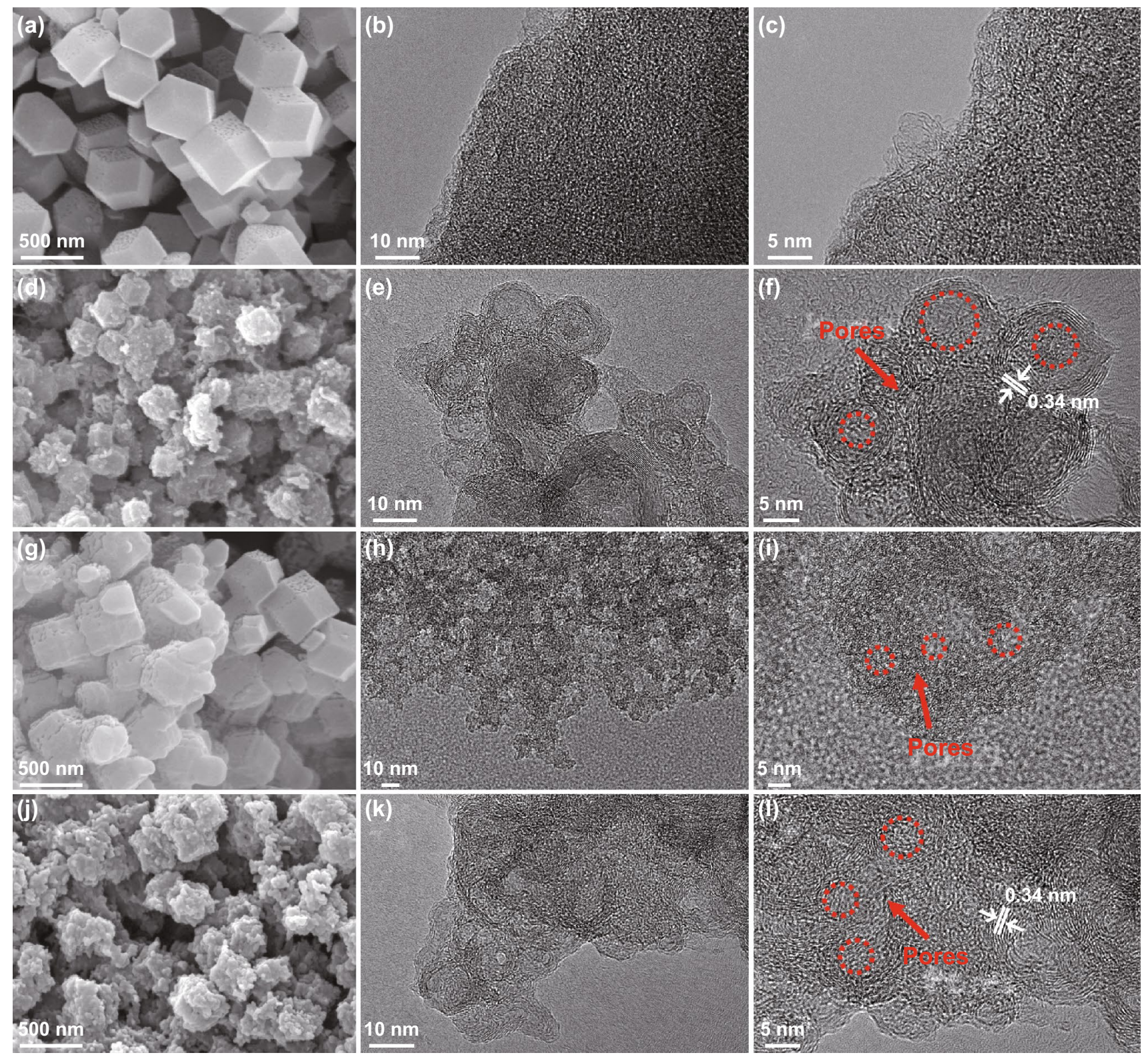

Fig. 3 SEM and HRTEM images of a-c $\mathrm{Zn}_{100}-\mathrm{PC}$, d-f $\mathrm{Co}_{100}-\mathrm{PC}$, g-i $\mathrm{Zn}_{100}-\mathrm{APC}$ and $\mathbf{j}-\mathbf{l} \mathrm{Co}_{100}-\mathrm{APC}$

at $0.1 \mathrm{~A} \mathrm{~g}^{-1}$. Although featured with relatively large BET specific surface area, the electrochemical properties of $\mathrm{Zn}_{100}-\mathrm{PC}$ are seriously restricted by the narrow and inappropriate pore characteristics [60]. Specially, prominent microporous characteristic of $\mathrm{Zn}_{100}-\mathrm{PC}$ (80\% microporous volume proportion) has been presented. On the contrary, although possessing the relatively low BET specific surface area, the specific capacity of $\mathrm{Co}_{100}-\mathrm{PC}$ could be reached up to $40 \mathrm{mAh} \mathrm{g}^{-1}$, resulted from the abundant meso-/ macro-porosities. Combining with Fig. $2 \mathrm{e}, \mathrm{f}, \mathrm{Co}_{100}-\mathrm{PC}$ possesses suitable pore size range $\left(d_{50}=2.07 \mathrm{~nm} \sim d_{75}=\right.$ $27.27 \mathrm{~nm}$ ), resulting in the strong adsorption/desorption behaviors of solvated $\mathrm{PF}_{6}{ }^{-}$ion. The results above demonstrate that the adsorption/desorption of the solvated anion $\left(\mathrm{PF}_{6}{ }^{-}\right)$behaviors are mainly determined by the pore sizes of carbon materials and an appropriate pore size is more crucial than a high surface area in order to obtain high values of capacitance. Interestingly, after $\mathrm{KOH}$ chemical 

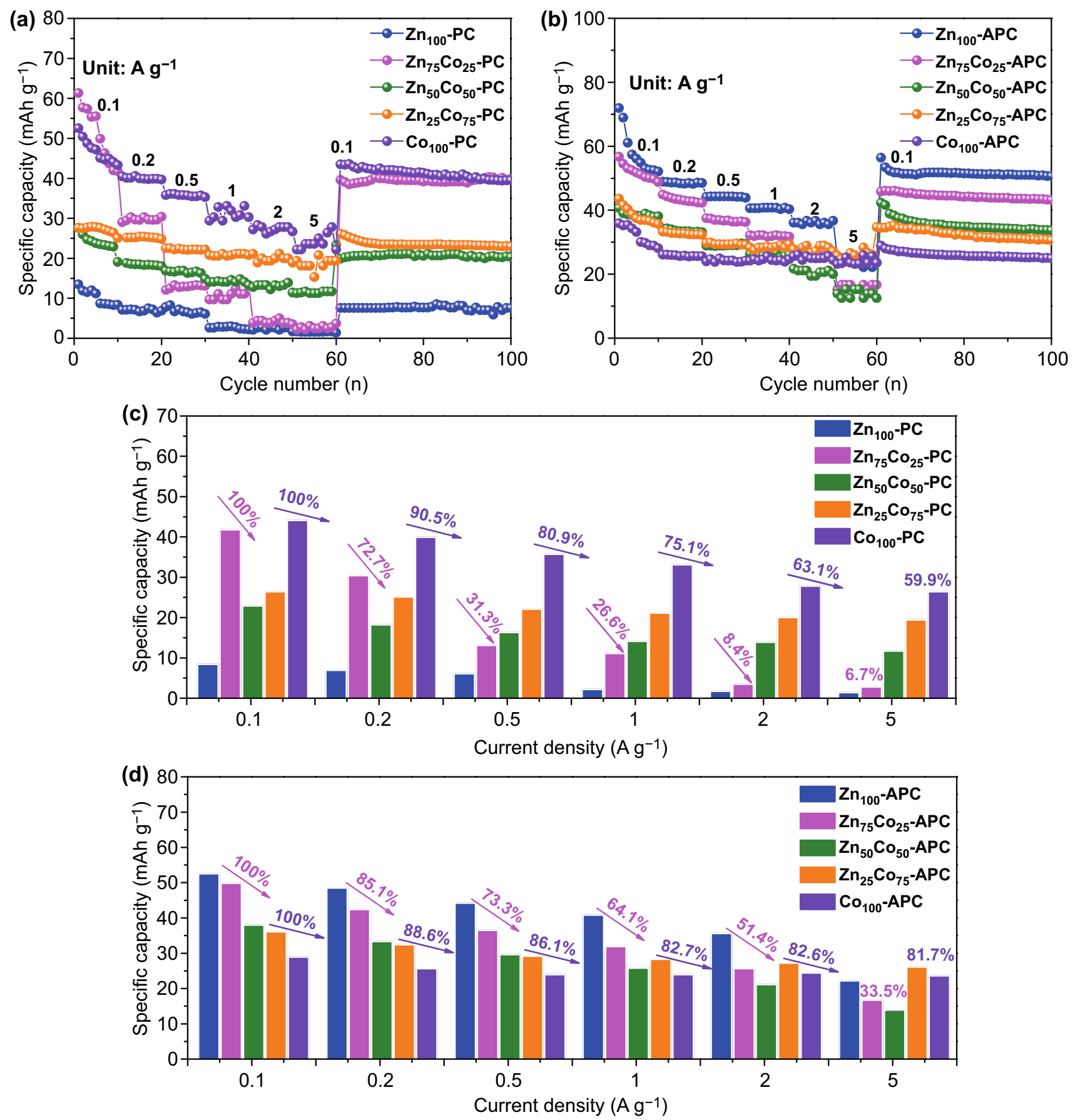

Fig. 4 Rate capabilities and comparisons of specific capacities at different current densities of $\mathbf{a}, \mathbf{c} \mathrm{Zn}_{x} \mathrm{Co}_{100-x}-\mathrm{PCs}$ and $\mathbf{b}, \mathbf{d} \mathrm{Zn}_{x} \mathrm{Co}_{100-x}-\mathrm{APCs}$

activation, $\mathrm{Zn}_{100}$-APC with enhanced electrochemical performances delivers a reversible specific capacity of $55 \mathrm{mAh}$ $\mathrm{g}^{-1}$ at $0.1 \mathrm{~A} \mathrm{~g}^{-1}$, whereas the electrochemical performances of $\mathrm{Co}_{100}$-APC are obviously decreased. The results above illustrate that the electrochemical performances of
$\mathrm{Zn}_{100}$-APC and $\mathrm{Co}_{100}$-APC are affected by the changed pore size distributions. It is found that the microporous volume proportion of $\mathrm{Zn}_{100}$-APC decreased to about $49 \%$, and $d_{50}$ and $d_{75}$ of $\mathrm{Zn}_{100}$-APC are increased up to 2.12 and $2.64 \mathrm{~nm}$, respectively, revealing the enlarged pore size 

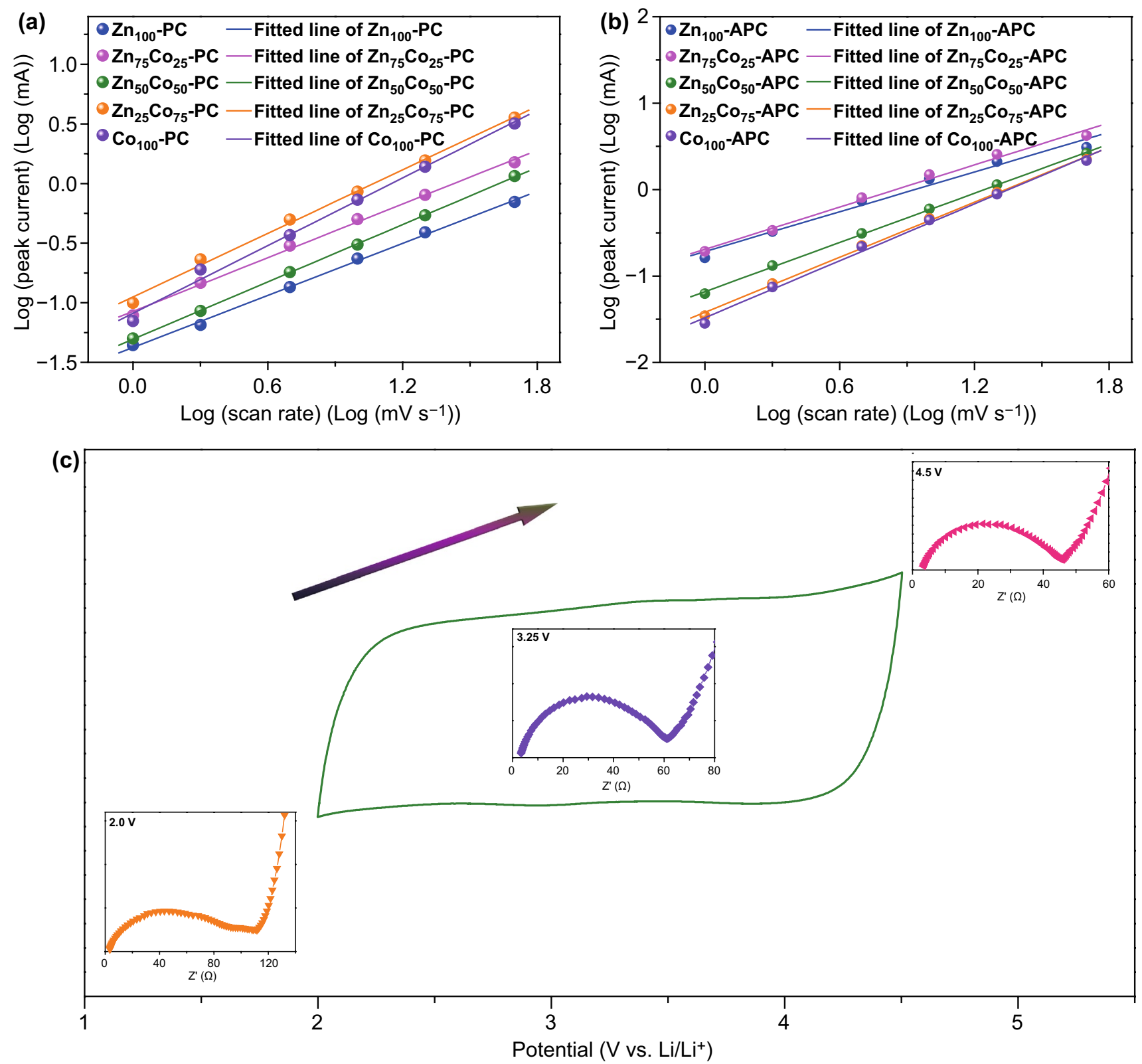

Fig. 5 Determination of the $b$-value using the relationship between the peak current and the scan rate of a $\mathrm{Zn}_{x} \mathrm{Co}_{100-x}-\mathrm{PCs}$ and $\mathbf{b} \mathrm{Zn}_{x} \mathrm{Co}_{100-x}-$ APCs. c Illustration of variation of Nyquist plots under different open-circuit voltages by taking $\mathrm{Co}_{100}-\mathrm{APC}$ as an example

distribution is beneficial for the adsorption/desorption of solvated $\mathrm{PF}_{6}{ }^{-}$ion. In addition, the $\mathrm{d}_{50}$ of $\mathrm{Co}_{100}$-APC have changed to $6.71 \mathrm{~nm}$ and the reduced electrochemical performances of $\mathrm{Co}_{100}$ - $\mathrm{APC}$ are attributed to the less porosity of about $2 \mathrm{~nm}$. Meanwhile, $d_{25}(10.06 \mathrm{~nm}), d_{50}(33.75 \mathrm{~nm})$, and $d_{75}(51.60 \mathrm{~nm})$ of $\mathrm{Zn}_{75} \mathrm{Co}_{25}-\mathrm{PC}$ are altered to 2.11, 2.96, and $17.37 \mathrm{~nm}$ after chemical activation. Because of the increased pore volume proportion in $2 \sim 3 \mathrm{~nm}$, the electrochemical performance of $\mathrm{Zn}_{75} \mathrm{Co}_{25}$-APC has been significantly improved. The above-mentioned results demonstrate that $2 \sim 3 \mathrm{~nm}$ pore size could bring out the strong adsorption/desorption behavior of solvated $\mathrm{PF}_{6}{ }^{-}$ions. Moreover, it is obvious that the rate performances of carbon materials derived from $\mathrm{Zn}_{x} \mathrm{Co}_{100-x}$-ZIFs with relatively high Co content could be boosted, resulting from the graphitization effect accompanied with enhanced electronic 

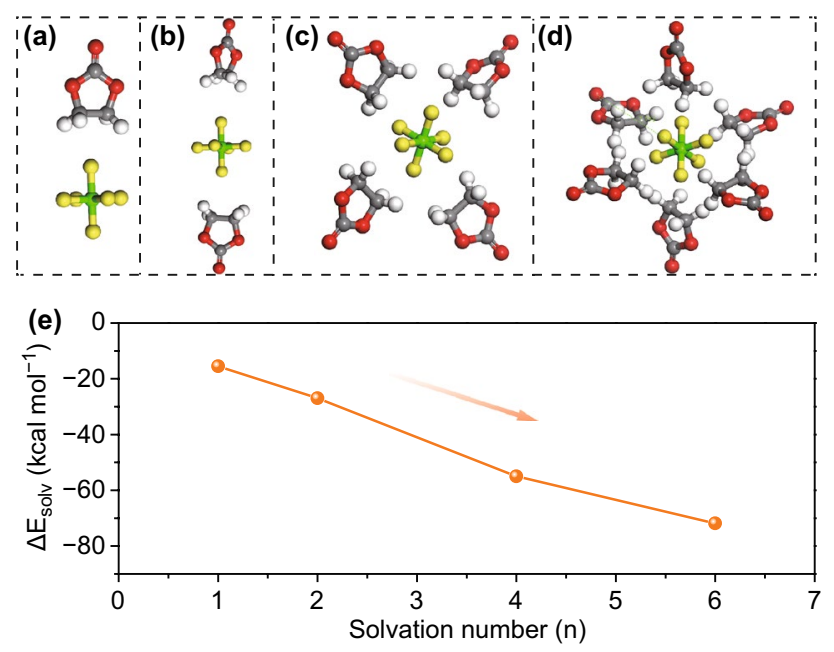

(f)
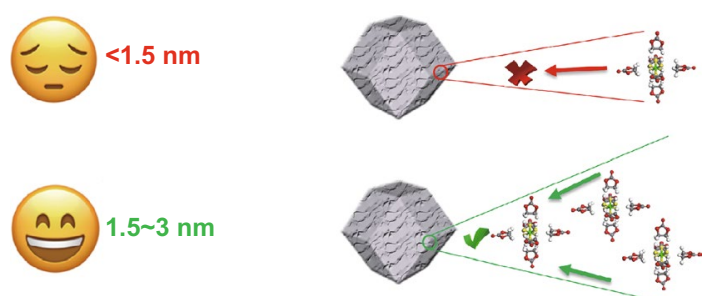

Fig. 6 Optimized solvation structures of $\mathrm{PF}_{6}{ }^{-}(\mathrm{EC})_{i}(i=1,2,4,6)$ by DFT calculations: a $\mathrm{PF}_{6}{ }^{-}(\mathrm{EC})_{1}$, b $\mathrm{PF}_{6}{ }^{-}(\mathrm{EC})_{2}, \mathbf{c} \mathrm{PF}_{6}{ }^{-}(\mathrm{EC})_{4}$ and $\mathbf{d}$ $\mathrm{PF}_{6}{ }^{-}(\mathrm{EC})_{6}$. e Variation tendency of solvation energies of $\mathrm{PF}_{6}{ }^{-}(\mathrm{EC})_{i}$ as a function of the solvation number. $\mathbf{f}$ Schematic illustration of electrosorption of solvated $\mathrm{PF}_{6}{ }^{-}$ions with a finite pore size

conductivity [61]. Furthermore, the XPS measurements have been carried out to verify the effect on capacity of $\mathrm{N}$ species. The XPS survey spectra and the elemental contents of $\mathrm{Zn}_{x} \mathrm{Co}_{100-x}-\mathrm{PCs}$ and $\mathrm{Zn}_{x} \mathrm{Co}_{100-x}$-APCs are presented in Fig. S4 and Table S1, respectively. The results demonstrate that $\mathrm{Zn}_{x} \mathrm{Co}_{100-x}$-APCs almost exhibit the similar chemical environment, which could further highlight the effect of pore sizes of carbon materials for the capacity contribution. In addition, $\mathrm{Zn}_{100}-\mathrm{PC}$ with relatively high $\mathrm{N}$ contents of $20.59 \%$ possesses the dissatisfactory electrochemical performances, which illustrates that the $\mathrm{N}$-doping effect is not preponderant in the capacity contribution and the appropriate pore size plays the vital role in the high capacity.

In order to better understand the adsorption/desorption behavior of the obtained material for solvated $\mathrm{PF}_{6}{ }^{-}$ion, kinetic analysis based on $\mathrm{CV}$ measurements with different scan rates range from 1 to $50 \mathrm{mV} \mathrm{s}^{-1}$ is carried out (Figs. S5 and S6). The CV curves of $\mathrm{Zn}_{x} \mathrm{Co}_{100-x}-\mathrm{PCs}$ and $\mathrm{Zn}_{x} \mathrm{Co}_{100-x}$-APCs at different scan rates show a quasirectangular shape with slight deformation, illustrating a dominant electric double-layer behavior with pseudocapacitance contribution. In addition, the $\mathrm{CV}$ curves of $\mathrm{Zn}_{x} \mathrm{Co}_{100-x}$-PCs and $\mathrm{Zn}_{x} \mathrm{Co}_{100-x}$-APCs show the unobvious deformation at the high scan rate as the proportion of cobalt ions increases, attributing to the graphitic crystallization with enhanced electron transfer. Generally, two types of charge-storage mechanisms are widely discussed, namely the surface-induced capacitive behavior and the diffusioncontrolled process $[62,63]$. The surface-induced capacitive behavior includes the faradaic behavior from the surface redox reaction and the electrical double-layer behavior from ion adsorption/desorption. The diffusion-controlled process is primarily originated from insertion of electrolyte ions. The peak current (i) and the scan rate ( $v$ ) follow the power law, which are shown in Eqs. 4 and 5 [64-66]:

$i=a \nu^{b}$

$\log (i)=b \log (v)+\log a$

where $a$ and $b$ stand for variable parameters. Importantly, on account of the $b$-value, the different electrochemical storage behavior can be classified. When $b$-value is close to 0.5 , it indicates the dominating diffusion-controlled process. On the contrary, when the $b$-value is near 1 , the storage capacity mostly originates from the surface-induced capacitive process. Figure 5a, b shows the fitted lines of $\mathrm{Zn}_{x} \mathrm{Co}_{100-x}-\mathrm{PCs}$ and $\mathrm{Zn}_{x} \mathrm{Co}_{100-x}$-APCs derived from the anodic peaks located $3.25 \mathrm{~V}$ and the corresponding $b$-values are calculated. The $b$-value of $\mathrm{Zn}_{100}-\mathrm{PC}, \mathrm{Zn}_{75} \mathrm{Co}_{25}-\mathrm{PC}, \mathrm{Zn}_{50} \mathrm{Co}_{50}-\mathrm{PC}$, $\mathrm{Zn}_{25} \mathrm{Co}_{75}-\mathrm{PC}$, and $\mathrm{Co}_{100}-\mathrm{PC}$ is $0.73,0.75,0.80,0.88$, and 0.94 , respectively, revealing that the intensive graphitization could boost the surface-induced capacitive kinetics. Importantly, after $\mathrm{KOH}$ chemical activation, the $b$-value of $\mathrm{Zn}_{100}-\mathrm{APC}, \mathrm{Zn}_{75} \mathrm{Co}_{25}$-APC, $\mathrm{Zn}_{50} \mathrm{Co}_{50}$-APC, $\mathrm{Zn}_{25} \mathrm{Co}_{75}$-APC and $\mathrm{Co}_{100}$-APC is reached up to 0.76, 0.81, 0.94, 1.06, and 1.09 , respectively, demonstrating that the surface-induced capacitive behavior could be improved by increasing meso/ macroporosities. The results above illustrate that increased electronic conductivity triggered by graphitization and rapid ion transport originated from meso/macroporosities could synergistically boost the surface-induced capacitive behavior. In other words, surface-induced capacitive behavior of carbon material could be promoted by enhancing the graphitization and meso/macroporosities.

As shown in Figs. S7 and S8, the Nyquist plots consisted of an intercept of the real axis about $R_{\mathrm{s}}$ (the resistance of materials in the cell, containing electrode, electrolyte, and separation), a semicircle in middle-high-frequency about $R_{\mathrm{ct}}$ 


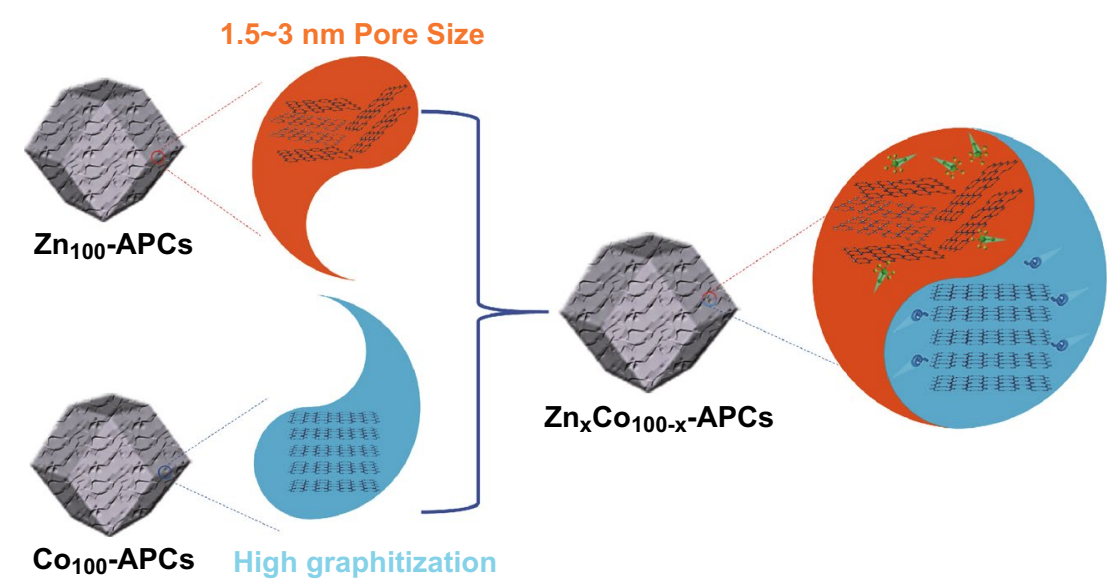

Fig. 7 Schematic illustration of the synthesis of the desired carbon cathode through the ingenious incorporation of high graphitization and appropriate pore size distribution

(the resistance of charge transfer) and a sloping straight line in low frequency about $Z_{\mathrm{W}}$ (corresponding to the capacitive behavior linked with the $\mathrm{PF}_{6}{ }^{-}$ion adsorption in the whole porous carbon network) [67-69]. Moreover, it is obvious that the diameter of the semicircle at medium-high-frequency region decreases as there is an increase in potential from 2 to $4.5 \mathrm{~V}$, showing the occurrence of the absorption of $\mathrm{PF}_{6}{ }^{-}$anion on the surface of electrode material, which can enhance the electronic conductivity (Fig. 5c). The $\sigma_{\mathrm{W}}$ values can be obtained from the slope of the $Z^{\prime}$ and $\omega^{-1 / 2}$ plot in the Warburg region, which could estimate the $\mathrm{PF}_{6}{ }^{-}$transfer. The enlargement of the graphitization degree with the proportion of cobalt ions could reduce the $\sigma_{\mathrm{W}}$ value, attributing to the enhancement of the electronic conductivity. Moreover, after 100 cycles at $0.1 \mathrm{~A} \mathrm{~g}^{-1}, R_{\mathrm{ct}}$ and $\sigma_{\mathrm{W}}$ values of $\mathrm{Zn}_{x} \mathrm{Co}_{100-x}-\mathrm{PCs}$ and $\mathrm{Zn}_{x} \mathrm{Co}_{100-x}-\mathrm{APCs}$ are increased under different open-circuit voltages, which indicates the deteriorated performance, resulted from the destroyed structures of electrode materials.

\subsection{Theoretical Calculation and Analysis of Solvated $\mathrm{PF}_{6}^{-}$Ion}

The DFT calculations have been performed to gain insight into the optimal structure of solvated $\mathrm{PF}_{6}{ }^{-}$ion. The solvation structures of $\mathrm{PF}_{6}{ }^{-}$ion have been firstly examined in $\mathrm{EC}$ molecules [70-72]. The optimized structures for $\mathrm{PF}_{6}{ }^{-}$(EC) $i$ $(i=1,2,4,6)$ have been present in Fig. 6a-d, respectively. In view of the asymmetric nature of the EC molecule, the position of the methyl group was switched prior to each optimization until the lowest energy solvation structure was found. Moreover, the solvation energy $\left(\Delta E_{\text {solv }}\right)$ has been calculated by Eq. 6 :

$\Delta E_{\mathrm{solv}}=E\left[P F_{6}^{-}(E C)_{i}\right]-E\left[P F_{6}^{-}\right]-E[E C] x i$

where $\mathrm{E}\left[\mathrm{PF}_{6}{ }^{-}(\mathrm{EC})_{i}\right]$ represents the electronic energy for $\mathrm{PF}_{6}{ }^{-}(\mathrm{EC})_{i}, \mathrm{E}\left[\mathrm{PF}_{6}{ }^{-}\right]$represents the electronic energy for the $\mathrm{PF}_{6}{ }^{-}$ion, $\mathrm{E}[\mathrm{EC}]$ represents the electronic energy for the solvent $\mathrm{EC}$ molecule, and $\mathrm{i}$ is the solvation number. Table S2 lists the specific calculated values of solvation energies of $\mathrm{PF}_{6}{ }^{-}(\mathrm{EC})_{i}$ structures, and Fig. 6e shows the variation tendency of solvation energy as a function of the solvation number. Importantly, it is found that the solvation process of $\mathrm{PF}_{6}{ }^{-}$ion accompanying with $\mathrm{EC}$ is spontaneous and the $\mathrm{PF}_{6}{ }^{-}(\mathrm{EC})_{6}$ possesses the lowest solvation energy of $-71.84 \mathrm{kcal} \mathrm{mol}^{-1}$. Meanwhile, the DMC molecule has also been examined for the solvation structures of $\mathrm{PF}_{6}{ }^{-}$ion and the related solvation energies of $\mathrm{PF}_{6}{ }^{-}(\mathrm{DMC})_{i}$ structures are listed in Fig. S9 and Table S3. Note that the EC molecule is inclined to combine with $\mathrm{PF}_{6}{ }^{-}$ion to form the stable solvation structure and the $\mathrm{PF}_{6}{ }^{-}(\mathrm{EC})_{6}$ is the optimized solvation structure. Thus, the optimized solvation structure of $\mathrm{PF}_{6}{ }^{-}(\mathrm{EC})_{6}$ mainly exists in the $1 \mathrm{~mol} \mathrm{~L}^{-1} \mathrm{LiPF}_{6}$ solution system (EC and DMC (1:1, v/v) with $5 \mathrm{wt} \%$ FEC) and the size of $\mathrm{PF}_{6}{ }^{-}(\mathrm{EC})_{6}$ structure is about $1.5 \mathrm{~nm}$ [73]. The DFT calculation greatly supports the experimental results above, which reveals that the pores smaller than solvated $\mathrm{PF}_{6}{ }^{-}$ions size of about $1.5 \mathrm{~nm}$ are inaccessible for energy storage and the pore size of carbon substantially becomes larger than the size of solvated $\mathrm{PF}_{6}{ }^{-}$ions to adequately accommodate diffuse charge layers. Moreover, in consideration of the 

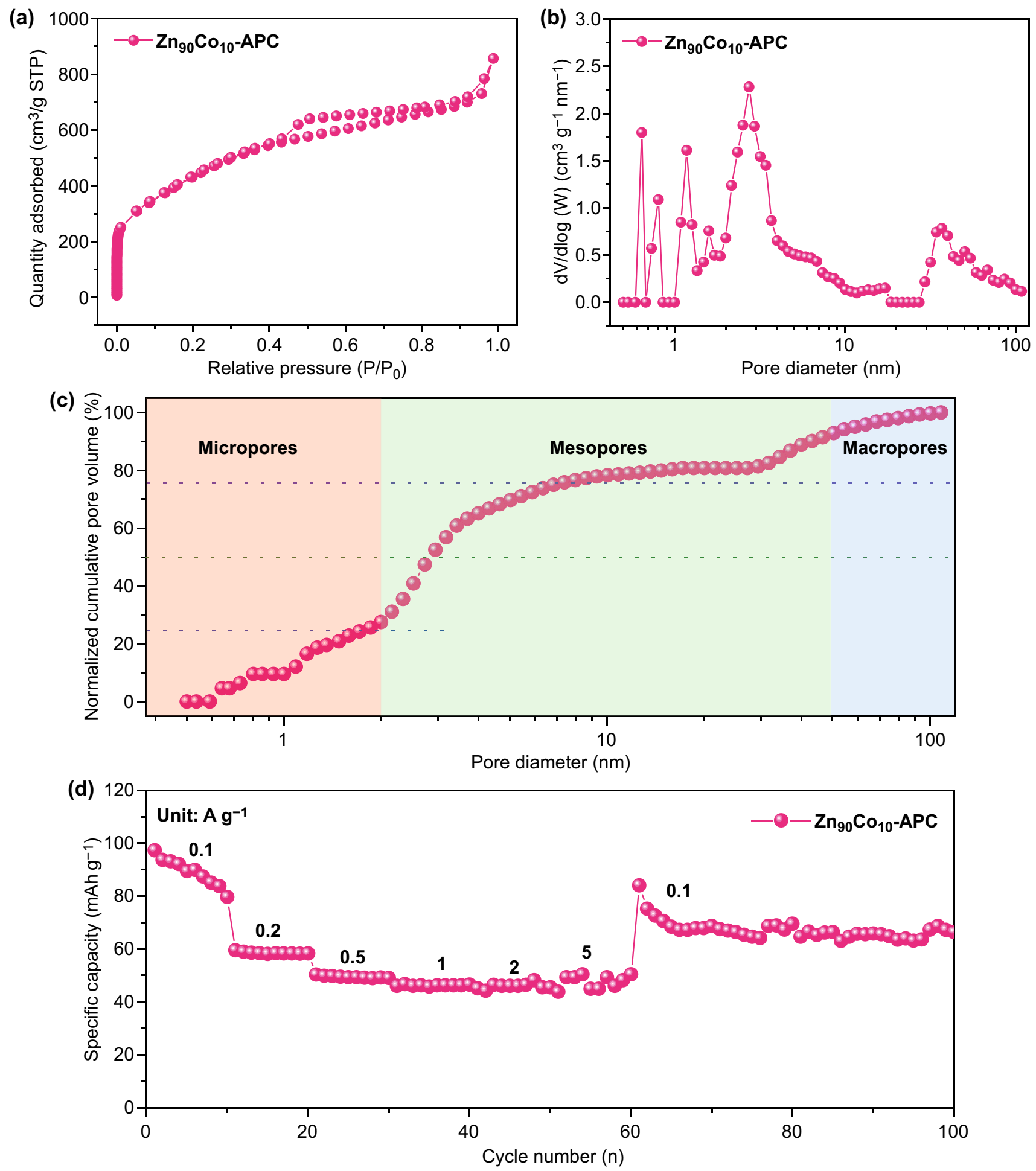

Fig. 8 a $\mathrm{N}_{2}$ adsorption-desorption isotherms, b pore size distribution curves, $\mathbf{c}$ normalized cumulative pore size distributions and $\mathbf{d}$ rate capabilities of $\mathrm{Zn}_{90} \mathrm{Co}_{10}$-APC

compact layers from adjacent pore walls, the pores lower than twice the size of the solvated $\mathrm{PF}_{6}{ }^{-}$ions could bring out desired capacitive performances (Fig. 6f). In summary, on the basis of DFT calculations, $1.5 \sim 3 \mathrm{~nm}$ pore size could 

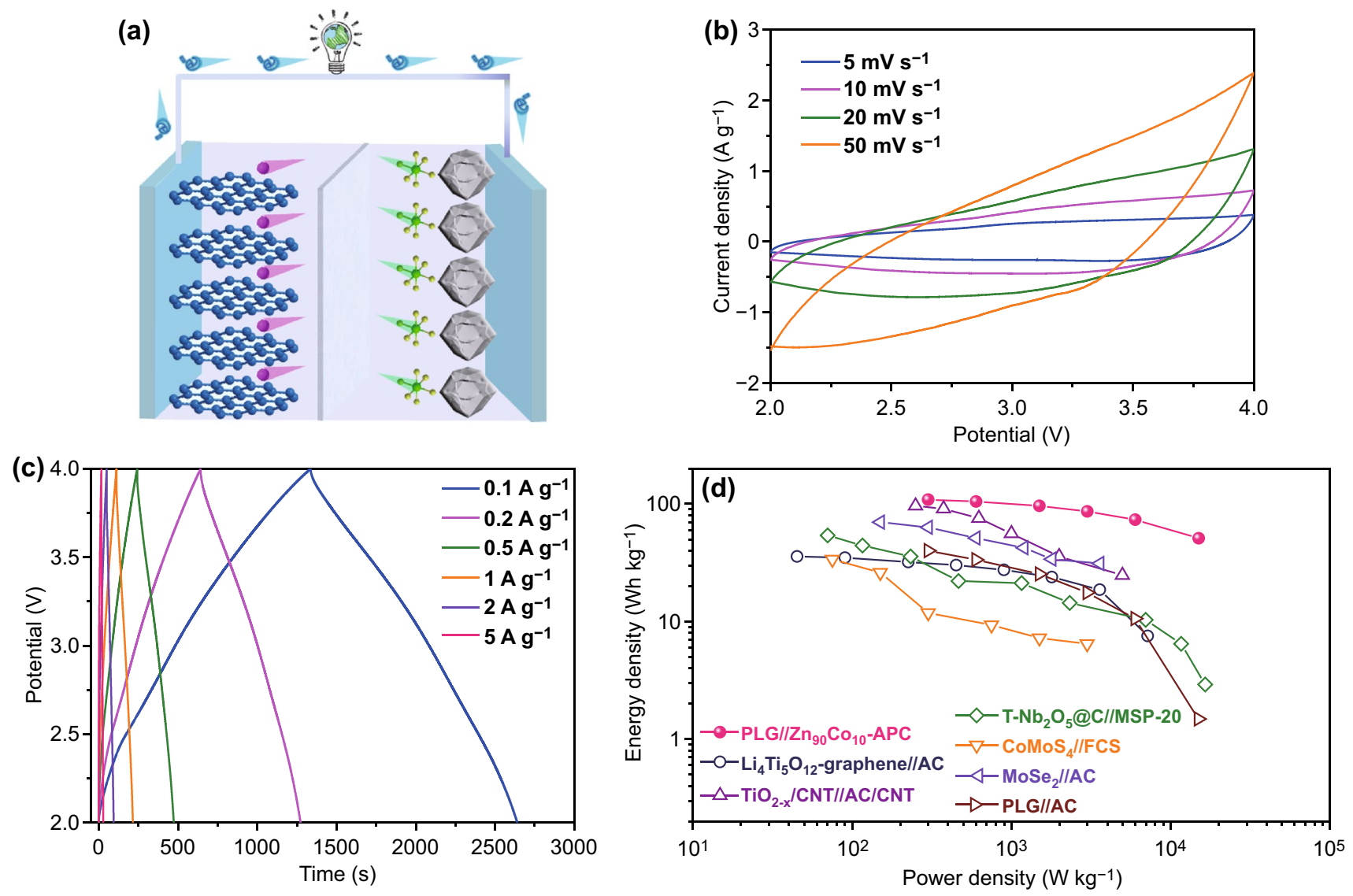

Fig. 9 a Schematic illustration of the charge-storage mechanisms for the LICs. b CV curves and c GCD profiles of PLG//Zn $\mathrm{n}_{90} \mathrm{Co}_{10}-\mathrm{APC}$ LIC. d Ragone plots of this work compared with other reported literatures

trigger strong adsorption/desorption behavior of solvated $\mathrm{PF}_{6}{ }^{-}$ions, which is well consistent with experimental results above.

\subsection{Electrochemical Performance of LICs}

In considerations of the results above, through the ingenious incorporation of high graphitization and appropriate pore size distribution, desired carbon cathode could be reasonably engineered and $\mathrm{Zn}_{90} \mathrm{Co}_{10}$-APC has been elaborately designed (Figs. 7 and S10). Thanks to the synergistic effect of graphitization and appropriate pore size distribution, $\mathrm{Zn}_{90} \mathrm{Co}_{10-}$ APC exhibits the most outstanding adsorption/ desorption behavior of solvated $\mathrm{PF}_{6}{ }^{-}$ions among the asprepared carbon samples (Fig. 8 and Table 1). $\mathrm{Zn}_{90} \mathrm{Co}_{10} \mathrm{APC}$ shows a high specific capacity of $\sim 100 \mathrm{mAh} \mathrm{g}^{-1}$ at the current density of $0.1 \mathrm{~A} \mathrm{~g} \mathrm{~g}^{-1}$ and could still retain $50 \mathrm{mAh} \mathrm{g}^{-1}$ even at the high current density of $5 \mathrm{~A} \mathrm{~g}^{-1}$, showing an excellent rate capability. Generally, commercialize LICs are generally composed of graphite anode and AC cathode. The theoretical capacity of graphite anode is $372 \mathrm{mAh} \mathrm{g}^{-1}$, and the detailed electrochemical performances have been recorded (Fig. S11). In order to evaluate the superiority of $\mathrm{Zn}_{90} \mathrm{Co}_{10} \mathrm{APC}$ sample as the cathode, the pre-lithiated graphite (PLG) as anode of LIC has been utilized in this work and the related schematic illustration of the chargestorage mechanisms is shown in Fig. 9a. As shown in Fig. 9b, c, the ideal rectangular shape CV curves with slight deviations are observed and the slopes of GCD profiles are not strictly linear with unobvious distortion, demonstrating the collaboration of two types of charge-storage mechanisms (faradaic and non-faradaic behaviors) [74-76]. The specific capacitances (based on the total mass of cathode and anode) of PLG//Zn ${ }_{90} \mathrm{Co}_{10}$-APC LIC are 65.1, 62.9, 57.6, 51.7, 44.1, and $30.55 \mathrm{~F} \mathrm{~g}^{-1}$ at the current densities of $0.1,0.2,0.5,1$, 2 , and $5 \mathrm{~A} \mathrm{~g}^{-1}$, respectively. Notably, PLG//Zn ${ }_{90} \mathrm{Co}_{10}$-APC 
LIC presents the high energy density of $108 \mathrm{Wh} \mathrm{kg}^{-1}$ at power density of $300 \mathrm{~W} \mathrm{~kg}^{-1}$. The energy density could still maintain $51 \mathrm{Wh} \mathrm{kg}^{-1}$ at a relatively high power density of $15,000 \mathrm{~W} \mathrm{~kg}^{-1}$. Moreover, as shown in Figs. $9 \mathrm{~d}$ and S12, the $\mathrm{PLG} / / \mathrm{Zn}_{90} \mathrm{Co}_{10}$-APC LIC presents superior energy/power characteristics compared to other previously reported LICs, such as $\mathrm{Li}_{4} \mathrm{Ti}_{5} \mathrm{O}_{12}$-graphene//AC [77], $\mathrm{TiO}_{2-\mathrm{x}} / \mathrm{CNT} / / \mathrm{AC} /$ CNT [78], $T-\mathrm{Nb}_{2} \mathrm{O}_{5} @ \mathrm{C} / / \mathrm{MSP}-20$ [79], $\mathrm{CoMoS}_{4} / / \mathrm{FCS}$ [80], $\mathrm{MoSe}_{2} / / \mathrm{AC}$ [81], $\mathrm{Fe}_{3} \mathrm{O}_{4} @ \mathrm{C} / / \mathrm{a}-\mathrm{EW}-\mathrm{NaCl}$ [82], and CNF// PANi@CNF-10 [83], and PLG//AC. Significantly, the PLG// $\mathrm{Zn}_{90} \mathrm{Co}_{10}$-APC LIC exhibits the good long-term ability with 10,000 cycles in the potential window of 2.0-4.0 V (Fig. $\mathrm{S} 13)$. Moreover, in consideration of the potential drop $(\Delta \mathrm{V})$ originated from the GCD curves during the cyclic process, the potential drop of PLG//AC LIC is increased up to $1.4 \mathrm{~V}$, which is much larger than that of $\mathrm{PLG} / / \mathrm{Zn}_{90} \mathrm{Co}_{10}$-APC LIC, further revealing the $\mathrm{PLG} / / \mathrm{Zn}_{90} \mathrm{Co}_{10}$-APC LIC possesses better long-term ability compared to PLG//AC LIC (Fig. S14). This study is anticipated to offer an in-depth understanding of capacitive behavior of carbon cathode in $\mathrm{LiPF}_{6}$ electrolyte and afford more possibilities for directionally fabricating desired carbon cathode of high-performance LICs.

\section{Conclusion}

In this work, an orientated-designed pore size and graphitization engineering strategy of the carbon materials based on ZIFs has been successfully developed, greatly promoting comprehensive exploration of the relationship between the intrinsic features and capacitive behaviors of carbon cathodes. Meaningfully, it is found that an appropriate pore size is more important than a high surface area for enhanced capacity and the suitable pore sizes of $1.5 \sim 3 \mathrm{~nm}$ could match well with the solvated $\mathrm{PF}_{6}{ }^{-}$ion, bringing out the strong adsorption/desorption behavior. Significantly, in the $\mathrm{LiPF}_{6}$ electrolyte, the rate ability could be improved by enhancing the graphitization degree of carbon materials. Furthermore, it is found that the surface-induced capacitive kinetics of carbon could be promoted by enhancing the graphitization and meso/macroporosities. It is found that pore size of 1.5-3 nm could trigger strong adsorption/desorption behavior of solvated $\mathrm{PF}_{6}{ }^{-}$ions according to DFT calculations. Notably, thanks to the synergistic effect of graphitization and appropriate pore size distribution, $\mathrm{Zn}_{90} \mathrm{Co}_{10}$-APC shows the most excellent electrochemical performance and the assembly PLG//Zn ${ }_{90} \mathrm{Co}_{10}$-APC LIC exhibits the superior electrochemical performances compared to PLG//AC LIC. This in-depth investigation based on the fundamental understanding of capacitive behavior in $\mathrm{LiPF}_{6}$ electrolyte can offer the directed guidances for the rational design of carbon cathodes for high-performance LICs.

Acknowledgements This work was financially supported by National Key Research and Development Program of China (2018YFC1901605), the National Postdoctoral Program for Innovative Talents (BX201600192), Hunan Provincial Science and Technology Plan (2017TP1001) and Innovation Mover Program of Central South University (GCX20190893Y).

Open Access This article is licensed under a Creative Commons Attribution 4.0 International License, which permits use, sharing, adaptation, distribution and reproduction in any medium or format, as long as you give appropriate credit to the original author(s) and the source, provide a link to the Creative Commons licence, and indicate if changes were made. The images or other third party material in this article are included in the article's Creative Commons licence, unless indicated otherwise in a credit line to the material. If material is not included in the article's Creative Commons licence and your intended use is not permitted by statutory regulation or exceeds the permitted use, you will need to obtain permission directly from the copyright holder. To view a copy of this licence, visit http://creativecommons.org/licenses/by/4.0/.

Electronic supplementary material The online version of this article (https://doi.org/10.1007/s40820-020-00458-6) contains supplementary material, which is available to authorized users.

\section{References}

1. J. Ding, W. Hu, E. Paek, D. Mitlin, Review of hybrid ion capacitors: from aqueous to lithium to sodium. Chem. Rev. 118, 6457-6498 (2018). https://doi.org/10.1021/acs.chemr ev. 8 b00116

2. H. Wang, C. Zhu, D. Chao, Q. Yan, H.J. Fan, Nonaqueous hybrid lithium-ion and sodium-ion capacitors. Adv. Mater. 29, 1702093 (2017). https://doi.org/10.1002/adma.201702093

3. P. Cai, K. Zou, G. Zou, H. Hou, X. Ji, Quinone/ester-based oxygen functional group-incorporated full carbon Li-ion capacitor for enhanced performance. Nanoscale 12, 36773685 (2020). https://doi.org/10.1039/c9nr10339b

4. L. Zhao, S. Wang, F. Pan, Z. Tang, Z. Zhang, S. Zhong, J. Zhang, Thermal convection induced $\mathrm{TiO}_{2}$ microclews as superior electrode materials for lithium-ion batteries. J. Mater. Chem. A 6, 11688-11693 (2018). https://doi.org/10.1039/ C8TA03616K

5. B. Li, J. Zheng, H. Zhang, L. Jin, D. Yang et al., Electrode materials, electrolytes, and challenges in nonaqueous 
lithium-ion capacitors. Adv. Mater. 30, 1705670 (2018). https ://doi.org/10.1002/adma.201705670

6. D. Cao, C. Yin, D. Shi, Z. Fu, J. Zhang, C. Li, Cubic perovskite fluoride as open framework cathode for Na-ion batteries. Adv. Funct. Mater. 27, 1701130 (2017). https://doi. org/10.1002/adfm.201701130

7. Y. Han, J. Hu, C. Yin, Y. Zhang, J. Xie, D. Yin, C. Li, Ironbased fluorides of tetragonal tungsten bronze structure as potential cathodes for Na-ion batteries. J. Mater. Chem. A 4, 7382-7389 (2016). https://doi.org/10.1039/C6TA02061E

8. Y. Luan, R. Hu, Y. Fang, K. Zhu, K. Cheng et al., Nitrogen and phosphorus dual-doped multilayer graphene as universal anode for full carbon-based lithium and potassium ion capacitors. Nano-Micro Lett. 11, 30 (2019). https://doi.org/10.1007/ s40820-019-0260-6

9. X. Wang, L. Liu, Z. Niu, Carbon-based materials for lithiumion capacitors. Mater. Chem. Front. 3, 1265-1279 (2019). https://doi.org/10.1039/C9QM00062C

10. J. Huang, B. Zhao, T. Liu, J. Mou, Z. Jiang, J. Liu, H. Li, M. Liu, Wood-derived materials for advanced electrochemical energy storage devices. Adv. Funct. Mater. 29, 1902255 (2019). https://doi.org/10.1002/adfm.201902255

11. C. Li, X. Zhang, K. Wang, X. Sun, Y. Ma, High-power and long-life lithium-ion capacitors constructed from N-doped hierarchical carbon nanolayer cathode and mesoporous graphene anode. Carbon 140, 237-248 (2018). https://doi. org/10.1016/j.carbon.2018.08.044

12. Y. Ma, H. Chang, M. Zhang, Y. Chen, Graphene-based materials for lithium-ion hybrid supercapacitors. Adv. Mater. 27, 5296-5308 (2015). https://doi.org/10.1002/adma.201501622

13. P. Han, G. Xu, X. Han, J. Zhao, X. Zhou, G. Cui, Lithium ion capacitors in organic electrolyte system: scientific problems, material development, and key technologies. Adv. Energy Mater. 8, 1801243 (2018). https://doi.org/10.1002/aenm.20180 1243

14. D. Han, Z. Weng, P. Li, Y. Tao, C. Cui et al., Electrode thickness matching for achieving high-volumetric-performance lithium-ion capacitors. Energy Storage Mater. 18, 133-138 (2019). https://doi.org/10.1016/j.ensm.2019.01.020

15. C. Liu, B.B. Koyyalamudi, L. Li, S. Emani, C. Wang, L.L. Shaw, Improved capacitive energy storage via surface functionalization of activated carbon as cathodes for lithium ion capacitors. Carbon 109, 163-172 (2016). https://doi. org/10.1016/j.carbon.2016.07.071

16. K. Zou, P. Cai, C. Liu, J. Li, X. Gao et al., A kinetically wellmatched full-carbon sodium-ion capacitor. J. Mater. Chem. A 7, 13540-13549 (2019). https://doi.org/10.1039/C9TA03797G

17. J. Zhang, W. Lv, D. Zheng, Q. Liang, D.W. Wang, F. Kang, Q.H. Yang, The interplay of oxygen functional groups and folded texture in densified graphene electrodes for compact sodium-ion capacitors. Adv. Energy Mater. 8, 1702395 (2018). https://doi.org/10.1002/aenm.201702395

18. Q. Xia, H. Yang, M. Wang, M. Yang, Q. Guo, L. Wan, H. Xia, Y. Yu, High energy and high power lithium-ion capacitors based on boron and nitrogen dual-doped 3D carbon nanofibers as both cathode and anode. Adv. Energy Mater. 7, 1701336 (2017). https://doi.org/10.1002/aenm.201701336

19. P. Simon, Y. Gogotsi, Capacitive energy storage in nanostructured carbon electrolyte systems. Acc. Chem. Res. 46, 1094-1103 (2013). https://doi.org/10.1021/ar200306b

20. Y. Wang, Y. Song, Y. Xia, Electrochemical capacitors: mechanism, materials, systems, characterization and applications. Chem. Soc. Rev. 45, 5925-5950 (2016). https://doi. org/10.1039/C5CS00580A

21. J. Chmiola, G. Yushin, Y. Gogotsi, C. Portet, P. Simon, P.L. Taberna, Anomalous increase in carbon capacitance at pore sizes less than 1 nanometer. Science 313, 1760-1763 (2006). https://doi.org/10.1126/science.1132195

22. C. Largeot, C. Portet, J. Chmiola, P.L. Taberna, Y. Gogotsi, P. Simon, Relation between the ion size and pore size for an electric double-layer capacitor. J. Am. Chem. Soc. 130, 2730 2731 (2008). https://doi.org/10.1021/ja7106178

23. J. Huang, B.G. Sumpter, V. Meunier, A universal model for nanoporous carbon supercapacitors applicable to diverse pore regimes, carbon materials, and electrolytes. Chem. Eur. J. 14, 6614-6626 (2008). https://doi.org/10.1002/chem.200800639

24. S. Kondrat, C.R. Pérez, V. Presser, Y. Gogotsi, A.A. Kornyshev, Effect of pore size and its dispersity on the energy storage in nanoporous supercapacitors. Energy Environ. Sci. 5, 6474-6479 (2012). https://doi.org/10.1039/c2ee03092f

25. D. Weingarth, M. Zeiger, N. Jäckel, M. Aslan, G. Feng, V. Presser, Graphitization as a universal tool to tailor the potential-dependent capacitance of carbon supercapacitors. Adv. Energy Mater. 4, 1400316 (2014). https://doi.org/10.1002/ aenm.201400316

26. R.R. Salunkhe, C. Young, J. Tang, T. Takei, Y. Ide, N. Kobayashi, Y. Yamauchi, A high-performance supercapacitor cell based on ZIF-8-derived nanoporous carbon using an organic electrolyte. Chem. Commun. 52, 4764-4767 (2016). https:// doi.org/10.1039/C6CC00413J

27. Y. Gong, D. Li, C. Luo, Q. Fu, C. Pan, Highly porous graphitic biomass carbon as advanced electrode materials for supercapacitors. Green Chem. 19, 4132-4140 (2017). https://doi. org/10.1039/C7GC01681F

28. H. Wang, Q.L. Zhu, R. Zou, Q. Xu, Metal-organic frameworks for energy applications. Chem 2, 52-80 (2017). https://doi. org/10.1016/j.chempr.2016.12.002

29. R.R. Salunkhe, Y.V. Kaneti, J. Kim, J.H. Kim, Y. Yamauchi, Nanoarchitectures for metal-organic framework-derived nanoporous carbons toward supercapacitor applications. Acc. Chem. Res. 49, 2796-2806 (2016). https://doi.org/10.1021/ acs.accounts.6b00460

30. D.M. Chen, J.Y. Tian, Z.W. Wang, C.S. Liu, M. Chen, M. Du, An anionic $\mathrm{Na}(\mathrm{I})$-organic framework platform: separation of organic dyes and post-modification for highly sensitive detection of picric acid. Chem. Commun. 53, 10668-10671 (2017). https://doi.org/10.1039/C7CC06073D

31. D. Shi, R. Zheng, M.J. Sun, X. Cao, C.X. Sun et al., Semiconductive copper(I)-organic frameworks for efficient light-driven hydrogen generation without additional photosensitizers and 
cocatalysts. Angew. Chem. Int. Ed. 56, 14637-14641 (2017). https://doi.org/10.1002/anie.201709869

32. K.Y. Zou, Z.X. Li, Controllable syntheses of MOF-derived materials. Chem. Eur. J. 24, 6506-6518 (2018). https://doi. org/10.1002/chem.201705415

33. S. Dang, Q.L. Zhu, Q. Xu, Nanomaterials derived from metalorganic frameworks. Nat. Rev. Mater. 3, 17075 (2017). https ://doi.org/10.1038/natrevmats.2017.75

34. Y.V. Kaneti, J. Tang, R.R. Salunkhe, X. Jiang, A. Yu, K.C. $\mathrm{Wu}$, Y. Yamauchi, Nanoarchitectured design of porous materials and nanocomposites from metal-organic frameworks. Adv. Mater. 29, 1604898 (2017). https://doi.org/10.1002/ adma.201604898

35. D. Shi, R. Zheng, C.S. Liu, D.M. Chen, J. Zhao, M. Du, Dualfunctionalized mixed keggin- and lindqvist-type $\mathrm{Cu}_{24}$-based POM@MOF for visible-light-driven $\mathrm{H}_{2}$ and $\mathrm{O}_{2}$ Evolution. Inorg. Chem. 58, 7229-7235 (2019). https://doi.org/10.1021/ acs.inorgchem.9b00206

36. J. Tang, R.R. Salunkhe, J. Liu, N.L. Torad, M. Imura, S. Furukawa, Y. Yamauchi, Thermal conversion of core-shell metalorganic frameworks: a new method for selectively functionalized nanoporous hybrid carbon. J. Am. Chem. Soc. 137, 1572-1580 (2015). https://doi.org/10.1021/ja511539a

37. W. Guo, W. Xia, K. Cai, Y. Wu, B. Qiu, Z. Liang, C. Qu, R. Zou, Kinetic-controlled formation of bimetallic metal-organic framework hybrid structures. Small 13, 1702049 (2017). https ://doi.org/10.1002/smll.201702049

38. C.S. Liu, Z.H. Zhang, M. Chen, H. Zhao, F.H. Duan et al., Pore modulation of zirconium-organic frameworks for highefficiency detection of trace proteins. Chem. Commun. 53, 3941-3944 (2017). https://doi.org/10.1039/C7CC00029D

39. D.M. Chen, J.Y. Tian, C.S. Liu, M. Du, A bracket approach to improve the stability and gas sorption performance of a metalorganic framework via in situ incorporating the size-matching molecular building blocks. Chem. Commun. 52, 8413-8416 (2016). https://doi.org/10.1039/C6CC02359B

40. G. Zou, H. Hou, C.W. Foster, C.E. Banks, T. Guo, Y. Jiang, Y. Zhang, X. Ji, Advanced hierarchical vesicular carbon Codoped with S, P, N for high-rate sodium storage. Adv. Sci. 5, 1800241 (2018). https://doi.org/10.1002/advs.201800241

41. H. Hou, C.E. Banks, M. Jing, Y. Zhang, X. Ji, Carbon quantum dots and their derivative 3D porous carbon frameworks for sodium-ion batteries with ultralong cycle life. Adv. Mater. 27, 7861-7866 (2015). https://doi.org/10.1002/adma.201503816

42. T. Wu, C. Zhang, G. Zou, J. Hu, L. Zhu, X. Cao, H. Hou, $\mathrm{X}$. Ji, The bond evolution mechanism of covalent sulfurized carbon during electrochemical sodium storage process. Sci. China Mater. 62, 1127-1138 (2019). https://doi.org/10.1007/ s40843-019-9418-8

43. Y. Han, P. Qi, S. Li, X. Feng, J. Zhou, H. Li, S. Su, X. Li, B. Wang, A novel anode material derived from organic-coated ZIF-8 nanocomposites with high performance in lithium ion batteries. Chem. Commun. 50, 8057-8060 (2014). https://doi. org/10.1039/C4CC02691H

44. Z.X. Li, K.Y. Zou, X. Zhang, T. Han, Y. Yang, Hierarchically flower-like $\mathrm{N}$-doped porous carbon materials derived from an explosive 3-fold interpenetrating diamondoid copper metal-organic framework for a supercapacitor. Inorg. Chem. 55, 6552-6562 (2016). https://doi.org/10.1021/acs.inorg chem.6b00746

45. Z. Wu, Y. Wang, X. Liu, C. Lv, Y. Li, D. Wei, Z. Liu, Carbonnanomaterial-based flexible batteries for wearable electronics. Adv. Mater. 31, 1800716 (2019). https://doi.org/10.1002/ adma.201800716

46. R. Wang, G. Lu, W. Qiao, J. Yu, Catalytic graphitization of coal-based carbon materials with light rare earth elements. Langmuir 32, 8583-8592 (2016). https://doi.org/10.1021/acs. langmuir.6b02000

47. D. Ayillath Kutteri, I.W. Wang, A. Samanta, L. Li, J. Hu, Methane decomposition to tip and base grown carbon nanotubes and $\mathrm{CO}_{\mathrm{x}}$-free $\mathrm{H}_{2}$ over mono-and bimetallic $3 \mathrm{~d}$ transition metal catalysts. Catal. Sci. Technol. 8, 858-869 (2018). https ://doi.org/10.1039/C7CY01927K

48. W. Zhang, X. Jiang, X. Wang, Y.V. Kaneti, Y. Chen et al., Spontaneous weaving of graphitic carbon networks synthesized by pyrolysis of ZIF-67 crystals. Angew. Chem. Int. Ed. 56, 8435-8440 (2017). https://doi.org/10.1002/anie.20170 1252

49. P. Ge, H. Hou, X. Cao, S. Li, G. Zhao, T. Guo, C. Wang, X. $\mathrm{Ji}$, Multidimensional evolution of carbon structures underpinned by temperature-induced intermediate of chloride for sodium-ion batteries. Adv. Sci. 5, 1800080 (2018). https://doi. org/10.1002/advs.201800080

50. H. Hou, L. Shao, Y. Zhang, G. Zou, J. Chen, X. Ji, Largearea carbon nanosheets doped with phosphorus: a high-performance anode material for sodium-ion batteries. Adv. Sci. 4, 1600243 (2017). https://doi.org/10.1002/advs.201600243

51. Z. Wu, K. Liu, C. Lv, S. Zhong, Q. Wang et al., Ultrahighenergy density lithium-ion cable battery based on the carbonnanotube woven macrofilm. Small 14, 1800414 (2018). https ://doi.org/10.1002/smll.201800414

52. H.J. Peng, G.X. Hao, Z.H. Chu, Y.L. Cui, X.M. Lin, Y.P. Cai, From metal-organic framework to porous carbon polyhedron: toward highly reversible lithium storage. Inorg. Chem. 56, 10007-10012 (2017). https://doi.org/10.1021/acs.inorg chem. $7 \mathrm{~b} 01539$

53. Q. Wang, W. Xia, W. Guo, L. An, D. Xia, R. Zou, Functional zeolitic-imidazolate-framework-templated porous carbon materials for $\mathrm{CO}_{2}$ capture and enhanced capacitors. Chem. Asian J. 8, 1879-1885 (2013). https://doi.org/10.1002/ asia. 201300147

54. M. Ding, W. Shi, L. Guo, Z.Y. Leong, A. Baji, H.Y. Yang, Bimetallic metal-organic framework derived porous carbon nanostructures for high performance membrane capacitive desalination. J. Mater. Chem. A 5, 6113-6121 (2017). https:// doi.org/10.1039/C7TA00339K

55. H. Peng, B. Yao, X. Wei, T. Liu, T. Kou, P. Xiao, Y. Zhang, Y. $\mathrm{Li}$, Pore and heteroatom engineered carbon foams for supercapacitors. Adv. Energy Mater. 9, 1803665 (2019). https://doi. org/10.1002/aenm.201803665

56. M. Wang, B. Liu, H. Chen, D. Yang, H. Li, N/O codoped porous carbons with layered structure for high-rate 
performance supercapacitors. ACS Sustain. Chem. Eng. 7, 11219-11227 (2019). https://doi.org/10.1021/acssuschem eng.9b00541

57. J. Li, H. Wei, Y. Peng, L. Geng, L. Zhu et al., A multifunctional self-healing G-PyB/KCl hydrogel: smart conductive, rapid room-temperature phase-selective gelation, and ultrasensitive detection of alpha-fetoprotein. Chem. Commun. 55, 7922-7925 (2019). https://doi.org/10.1039/C9CC02770J

58. N. Jäckel, P. Simon, Y. Gogotsi, V. Presser, Increase in capacitance by subnanometer pores in carbon. ACS Energy Lett. 1, 1262-1265 (2016). https://doi.org/10.1021/acsenergyl ett.6b00516

59. K.Y. Zou, Y.C. Liu, Y.F. Jiang, C.Y. Yu, M.L. Yue, Z.X. Li, Benzoate acid-dependent lattice dimension of Co-MOFs and MOF-derived $\mathrm{CoS}_{2} @ \mathrm{CNTs}$ with tunable pore diameters for supercapacitors. Inorg. Chem. 56, 6184-6196 (2017). https:// doi.org/10.1021/acs.inorgchem.7b00200

60. R. Wang, D. Jin, Y. Zhang, S. Wang, J. Lang, X. Yan, L. Zhang, Engineering metal organic framework derived 3D nanostructures for high performance hybrid supercapacitors. J. Mater. Chem. A 5, 292-302 (2017). https://doi.org/10.1039/ C6TA09143A

61. H. Ma, H. Geng, B. Yao, M. Wu, C. Li, M. Zhang, F. Chi, L. Qu, Highly ordered graphene solid: an efficient platform for capacitive sodium-ion storage with ultrahigh volumetric capacity and superior rate capability. ACS Nano 13, 91619170 (2019). https://doi.org/10.1021/acsnano.9b03492

62. S. Yang, S. Wang, X. Liu, L. Li, Biomass derived interconnected hierarchical micro-meso-macro-porous carbon with ultrahigh capacitance for supercapacitors. Carbon 147, 540549 (2019). https://doi.org/10.1016/j.carbon.2019.03.023

63. C. Chang, M. Li, H. Wang, S. Wang, X. Liu, H. Liu, L. Li, A novel fabrication strategy for doped hierarchical porous biomass-derived carbon with high microporosity for ultrahighcapacitance supercapacitors. J. Mater. Chem. A 7, 1993919949 (2019). https://doi.org/10.1039/C9TA06210F

64. J. Wang, J. Polleux, J. Lim, B. Dunn, Pseudocapacitive contributions to electrochemical energy storage in $\mathrm{TiO}_{2}$ (anatase) nanoparticles. J. Phys. Chem. C 111, 14925-14931 (2007). https://doi.org/10.1021/jp074464w

65. S. Li, J. Chen, X. Gong, J. Wang, P.S. Lee, Holey graphenewrapped porous $\mathrm{TiNb}_{24} \mathrm{O}_{62}$ microparticles as high-performance intercalation pseudocapacitive anode materials for lithium-ion capacitors. NPG Asia Mater. 10, 406-416 (2018). https://doi.org/10.1038/s41427-018-0042-5

66. P. Zhang, X. Zhao, Z. Liu, F. Wang, Y. Huang et al., Exposed high-energy facets in ultradispersed sub-10 nm $\mathrm{SnO}_{2}$ nanocrystals anchored on graphene for pseudocapacitive sodium storage and high-performance quasi-solid-state sodium-ion capacitors. NPG Asia Mater. 10, 429-440 (2018). https://doi.org/10.1038/s41427-018-0049-y

67. S. Miyoshi, T. Akbay, T. Kurihara, T. Fukuda, A.T. Staykov, S. Ida, T. Ishihara, Fast diffusivity of $\mathrm{PF}_{6}{ }^{-}$anions in graphitic carbon for a dual-carbon rechargeable battery with superior rate property. J. Phys. Chem. C 120, 22887-22894 (2016). https://doi.org/10.1021/acs.jpcc.6b07957
68. P. Ge, S. Li, L. Xu, K. Zou, X. Gao et al., Hierarchical hollowmicrosphere metal-selenide@carbon composites with rational surface engineering for advanced sodium storage. Adv. Energy Mater. 9, 1803035 (2019). https://doi.org/10.1002/aenm.20180 3035

69. T. Thomberg, R. Väli, J. Eskusson, T. Romann, A. Jänes, Potassium salts based non-aqueous electrolytes for electrical double layer capacitors: a comparison with $\mathrm{LiPF}_{6}$ and $\mathrm{NaPF}_{6}$ cased electrolytes. J. Electrochem. Soc. 165, A3862-A3870 (2018). https://doi.org/10.1149/2.0661816jes

70. J.P. Perdew, K. Burke, M. Ernzerhof, Generalized gradient approximation made simple. Phys. Rev. Lett. 77, 3865-3868 (1996). https://doi.org/10.1103/PhysRevLett.77.3865

71. K. Tasaki, A. Goldberg, J.J. Liang, M. Winter, New insight into differences in cycling behaviors of a lithium-ion battery cell between the ethylene carbonate- and propylene carbonatebased electrolytes. ECS Trans. 33, 9-69 (2011). https://doi. org/10.1149/1.3563090

72. B. Delley, An all-electron numerical method for solving the local density functional for polyatomic molecules. J. Chem. Phys. 92, 508-517 (1990). https://doi.org/10.1063/1.458452

73. A. Karatrantos, Q. Cai, Effects of pore size and surface charge on $\mathrm{Na}$ ion storage in carbon nanopores. Phys. Chem. Chem. Phys. 18, 30761-30769 (2016). https://doi.org/10.1039/ $\mathrm{C} 6 \mathrm{CP} 04611 \mathrm{H}$

74. B. Yang, J. Chen, S. Lei, R. Guo, H. Li, S. Shi, X. Yan, Spontaneous growth of 3D framework carbon from sodium citrate for high energy- and power-density and long-life sodium-ion hybrid capacitors. Adv. Energy Mater. 8, 1702409 (2018). https://doi.org/10.1002/aenm.201702409

75. J. Ding, H. Wang, Z. Li, K. Cui, D. Karpuzov, X. Tan, A. Kohandehghan, D. Mitlin, Peanut shell hybrid sodium ion capacitor with extreme energy-power rivals lithium ion capacitors. Energy Environ. Sci. 8, 941-955 (2015). https:// doi.org/10.1039/C4EE02986K

76. S. Li, J. Chen, X. Gong, J. Wang, P.S. Lee, A nonpresodiate sodium-ion capacitor with high performance. Small 14, 1804035 (2018). https://doi.org/10.1002/smll.201804035

77. X. Zhang, C. Lu, H. Peng, X. Wang, Y. Zhang, Z. Wang, Y. Zhong, G. Wang, Influence of sintering temperature and graphene additives on the electrochemical performance of porous $\mathrm{Li}_{4} \mathrm{Ti}_{5} \mathrm{O}_{12}$ anode for lithium ion capacitor. Electrochim. Acta 246, 1237-1247 (2017). https://doi.org/10.1016/j.elect acta.2017.07.014

78. L.F. Que, F.D. Yu, Z.B. Wang, D.M. Gu, Pseudocapacitance of $\mathrm{TiO}_{2-\mathrm{x}} / \mathrm{CNT}$ anodes for high-performance quasi-solid-state Li-Ion and Na-Ion capacitors. Small 14, 1704508 (2018). https ://doi.org/10.1002/smll.201704508

79. E. Lim, C. Jo, H. Kim, M.H. Kim, Y. Mun et al., Facile synthesis of $\mathrm{Nb}_{2} \mathrm{O}_{5} @$ carbon core-shell nanocrystals with controlled crystalline structure for high-power anodes in hybrid supercapacitors. ACS Nano 9, 7497-7505 (2015). https://doi. org/10.1021/acsnano.5b02601

80. Y.K. Wang, W.B. Zhang, Y. Zhao, K. Li, L.B. Kong, Coprecipitation reaction system synthesis and lithium-ion capacitor energy storage application of the porous structural bimetallic 
sulfide $\mathrm{CoMoS}_{4}$ nanoparticles. ACS Omega 3, 8803-8812 (2018). https://doi.org/10.1021/acsomega.8b01408

81. H.J. Zhang, Y.K. Wang, L.B. Kong, A facile strategy for the synthesis of three-dimensional heterostructure self-assembled $\mathrm{MoSe}_{2}$ nanosheets and their application as an anode for highenergy lithium-ion hybrid capacitors. Nanoscale 11, 72637276 (2019). https://doi.org/10.1039/C9NR00164F

82. R. Shi, C. Han, H. Li, L. Xu, T. Zhang et al., NaCl-templated synthesis of hierarchical porous carbon with extremely large specific surface area and improved graphitization degree for high energy density lithium ion capacitors. J. Mater. Chem. A 6, 17057-17066 (2018). https://doi.org/10.1039/C8TA05853A

83. C. Han, J. Tong, X. Tang, D. Zhou, H. Duan, B. Li, G. Wang, Boost anion storage capacity using conductive polymer as a pseudocapacitive cathode for high-energy and flexible lithium ion capacitors. ACS Appl. Mater. Interfaces. 12, 10479-10489 (2020). https://doi.org/10.1021/acsami.9b22081 